\title{
TENSILE EMBRITTLEMENT OF TURBINE BLADE ALLOYS AFTFR HIGH-TEMPERATURE EXPOSURE
}

\author{
W. H. Chang \\ General Electric Company \\ Cincinnati, Ohio
}

\begin{abstract}
The tensile ductility of three $y^{\prime}$-strengthened, Ni-base superalloys is found to be reduced by high-temperature exposure. The cause of tensile embrittlement has been investigated by characterizing the effects of exposure temperature, time and atmosphere (air vs. vacuum), testing atmosphere (air vs. vacuum), strain rate and protective coatings. Results are presented to show that tensile embrittlement is environment-related, caused by interactions of nitrogen and probably also oxygen with the grain-boundary $v^{\prime}$ network which forms upon exposure as a result of the $\mathrm{MC}+\gamma \rightarrow \mathrm{M}_{23} \mathrm{C}_{6}+\gamma$ ' reaction. Two modes of interactions are identified. Static interactions result from contamination of the ' $y$ ' network by inward diffusion of the interstitials, associated with an apparent activation energy of 67 $\mathrm{kca} 1$ /mole. Dynamic interactions occur instantaneously during testing in air when the $\gamma^{\prime}$ network is exposed by surface cracking. The dissolution and or adsorption of the interstitials is believed to lower the surface energy and fracture strength of the $\gamma^{\prime}$ phase. In the absence of environmental interactions, the intrinsic ductility of all three alloys is shown conclusively to be enhanced, rather than impaired, by high-temperature exposure.

The effects of strain rate and protective coatings are studied. High strain rates aggravate tensile embittlement by altering the sites of crack initiation and propagation. The efficacy of three types of coating in mitigating environmental interactions is illustrated and discussed in terms of coating composition, microstructure, thickness, and ductility.
\end{abstract}

\section{Introduction}

High-temperature turbine blades in jet engines are produced exclusively from " ${ }^{\prime}$-strengthened $\mathrm{Ni}$-base superalloys. As characteristic of all complex alloy systems, prolonged exposures at elevated temperatures lead to microstructural and property changes. The most common structural changes in $\mathrm{Ni}$-base superalloys consist of $\gamma$ ' agglomeration, carbide reactions, and formation of $\gamma^{\prime}$ network at the grain boundaries. These changes in representative blade alloys have been reported in the literature(1). Less well known, however, is the influence of structural changes on mechanical properties. In the turbine environment, the structure-property relationships are further complicated by oxidation and hot corrosion. Surface-stability studies on turbine alloys have thus far focused attention primarily on visually detectable products such as scaling, sulfidation, internal oxidation, alloy depletion 
and intergranular oxidation. The possibility of more subtle environmental effects, which are known to affect mechanical properties in metals or simple alloys at lower temperatures, $(2)$ appears to have hitherto received only scanty recognition in the case of turbine alloys. Prager conducted a comprehensive study of the tensile embrittlement of Rene' 4l(3). He attributed the embrittlement to dislocation pile-ups which initiate intergranular cracking to allow oxygen adsorption and, presumably, reduction in surface energy of the $\gamma / \gamma$ interface. More recently, environmental sensitivity of fatigue behavior, as reflected by differences either in testing atmospheres or in cycling frequency, has been reported for $\operatorname{Mar}-\operatorname{M200}(4,3)$, U700(6), and U500(7).

The present paper describes the results of an investigation concerning primarily the effect of high-temperature exposure on tensile ductility of a cast Ni-base turbine blade alloy, Rene' 80 . The properties of this high-strength alloy have been reported in the 1iterature (8). As shown in Fig. 1, Rene' 80 in the heat-treated condition has ample tensile ductility. The latter, however, is reduced by prolonged exposures at elevated temperatures, the effect being particularly pronounced in the neighborhood of $1600^{\circ} \mathrm{F}$. The primary objective of the present investigation was to establish the cause of what will be referred to as "tensile embrittlement". Early in the investigation, the embrittlement phenomenon was found to be related not only to microstructural changes but, more importantly, to increased sensitivity of these changes to hot air environment. This critical discovery broadened the scope of study to effects of protective coating. Furthermore, the environmental effects strongly suggested that tensile embrittlement would not be unique to Rene' 80 , but should be common to all Ni-base alloys which undergo similar structural changes. The investigation was therefore extended to Rene' 77 and Rene' 100 to further elucidate the embrittling mechanism.

\section{Experimental Procedure}

Although no concrete ideas existed prior to this investigation, it appeared highly probable that the embrittlement phenomenon would be related to structural and/or compositional changes, the latter including internal re-partitioning of alloying or tramp elements as well as mass transport through the surface. Isolating these changes therefore constituted the basis of the experimental approach. This was accomplished by characterizing the effects of five major variables consisting of exposure atmospheres, testing atmospheres, strain rates, surface removal, and protective coatings. Details of the experimental procedure are as follows:

Materia1s:

Several heats of each of the alloys, supplied by different sources, were investigated. There were no significant heat-to-heat differences either in chemistry or in embrittlement behavior. Consequently, only 


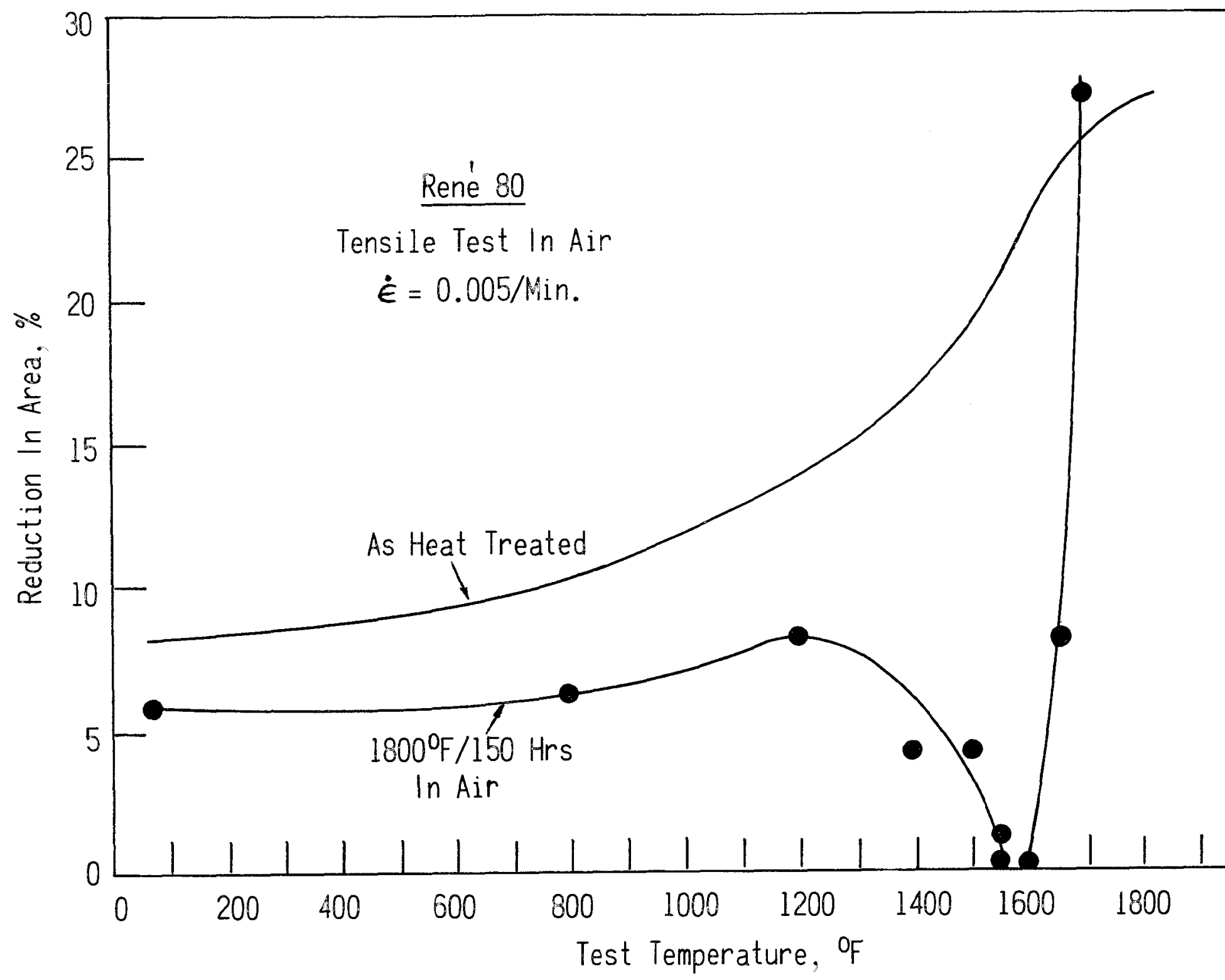

Figure 1. Effect of Air Exposure on Tensile Ductility of Rene' 80 . 
the nominal compositions of the alloys are given in Table 1 . All of the materials were purchased as precision-cast tensile bars with threaded ends, measuring about 3.5 in. overall length with a reduced section of approximately 0.25 in. dia. by 1.5 in. long. Some data were also obtained on directionally-solidified Rene' 80 and Ni3Al. These were grown as 3/8-in. dia. rods by the Bridgman technique and centerless ground into tensile specimens of 2 in. overall length with a gage section of 0.160 in. dia. by 0.5 in. long.

Table 1: Compositions of Alloys ${ }^{a, b}$

\begin{tabular}{|c|c|c|c|c|c|c|c|c|c|c|c|c|}
\hline \multirow[b]{2}{*}{ Alloy } & & \multicolumn{9}{|c|}{ Composition, w/o } & \multirow[b]{2}{*}{ Heat } & \multirow[b]{2}{*}{ Treatment } \\
\hline & & $\mathrm{C}$ & A1 & $\mathbf{T i}$ & $\mathrm{Cr}$ & $\mathrm{Co}$ & $W$ & Mo & $\overline{\mathrm{V}}$ & $\overline{\mathrm{BaI}}$ & & \\
\hline Rene' & 80 & 0.17 & 3.0 & 5.0 & 14.0 & 9.5 & 4.0 & 4.0 & - & $\mathrm{Ni}$ & $\begin{array}{l}2225^{\circ} \mathrm{F} / 2 \mathrm{Hr}, \\
1925^{\circ} \mathrm{F} / 4 \mathrm{Hr}\end{array}$ & $\begin{array}{l}2000^{\circ} \mathrm{F} / 4 \mathrm{Hr} \\
1550^{\circ} \mathrm{F} / 16 \mathrm{Hr}\end{array}$ \\
\hline Rene' $^{\prime}$ & 77 & 0.07 & 4.3 & 3.4 & 14.2 & 15.0 & - & 4.2 & - & $\mathrm{Ni}$ & $2125^{\circ} \mathrm{F} / 2 \mathrm{Hr}$ & $1400^{\circ} \mathrm{F} / 16 \mathrm{Hr}$ \\
\hline Rene' & 100 & 0.18 & 5.5 & 1.2 & 9.5 & 15.0 & - & 3.0 & 1.0 & $\mathrm{Ni}$ & $\begin{array}{l}2225^{\circ} \mathrm{F} / 2 \mathrm{Hr} \\
1925^{\circ} \mathrm{F} / 4 \mathrm{Hr}\end{array}$ & $\begin{array}{lll}2000^{\circ} \mathrm{F} / 14 \mathrm{IIr} \\
1550^{\circ} \mathrm{F} / 16 \mathrm{Hr}\end{array}$ \\
\hline $\mathrm{Ni}_{3} \mathrm{Al}$ & & & 12.75 & & & & & & & $\mathrm{Ni}$ & As Cast & \\
\hline
\end{tabular}

a. All compositions are nominal except $\mathrm{Ni}_{3} \Lambda 1$ which was analyzed

b. Minor elements in the Rene' alloys not included

Heat Treatment, Exposure, and Surface Preparation

All heat treatments were conducted in vacuum of $\sim 10^{-5}$ torr according to the schedules given in Table 1 . The heat-treated bars were centerless ground, reducing the gage section to $0.235 \mathrm{in}$. dia. by 1.25 in. long. After cleaning in acetone and water, the bars were exposed either in air or in vacuum of $\sim 10^{-5}$ torr. The exposure conditions ranged from $1650^{\circ}$ to $1900^{\circ} \mathrm{F}$ for durations of 25 to 750 hours.

Surface removal after exposure was found critical in that cold work generated by grinding tended to induce surface cracks during tensile testing, thereby affecting ductility in a manner to be described later. Surface polishing by chemical or electrochemical means could not be attempted as any localizcd attack would also cause surface crack initiation. Consequently, great care was taken to accomplish the last stages of surface removal by "soft" or "low-stress" centerless grinding to a surface finish of $8 \mathrm{rms}$. The bars were periodically examined by x-ray diffraction to check the quality of grinding.

Tensile Test

With a few exceptions noted later, tensile tests were conducted on Baldwin machines using either air or vacuum ( $10^{-5}$ torr $)$ atmospheres. Since embrittlement was most severe at $1600^{\circ} \mathrm{F}$, all tests were conducted at this temperature. The test temperature was controlled by chromelalumel (air) or $\mathrm{Pt}-\mathrm{Pt} / \mathrm{Rh}$ (vacuum) thermocouples attached to specimen gage section. The effect of strain rates was assessed, using nominal strain rates of $0.005,0.05$, and 0.5 per min. The strain rates were controlled by extensometers attached to the specimen gage section in 
air tcsts and to the cross head plates in vacuum tests. In either case, the specified strain rates were maintained only in the early part of the testing. It is for this reason that the effect of strain rate on ductility as presented in this work should be viewed only on an order of magnitude basis.

Metallography

Metallographic specimens were polished in a normal manner. The polished surface was generally first ctchod elcctrolytically in Murakami's agent $\left(60 \mathrm{ml}\right.$. of $16 \% \mathrm{KOH}, 60 \mathrm{ml}$. of $10 \% \mathrm{~K}_{3} \mathrm{Fe}(\mathrm{CN})_{6}$, and 100 $\mathrm{ml}$. of water, 3 volts) to reveal the carbide reactions. This was followed by an electrolytic etch in a mixture of $30 \mathrm{ml}$. phosphoric acid in $200 \mathrm{ml}$. of water, using $2-5$ volts. The later etch darkens the $\gamma$ matrix preferentially, providing excellent contrast to the unaffected $\gamma^{\prime}$ phase, especially in the grain boundaries.

In addition to light and electron microscopy, carbide reactions werc establishod by clcctrolytic cxtraction in a solution of $10 \% \mathrm{HCl}$ in methanol, followed by x-ray diffraction on a GE-XRD5 instrument, using $\mathrm{Cu}-\mathrm{K}$ radiation.

Coatings

Three types of coatings were evaluated which were Codep, MCrA1Y, and an experimental coating. Codep is an aluminide coaling applied by a pack method at $1925^{\circ} \mathrm{F}$, resulting in approximately two-mil thickness with an outermost layer of NiAl. The MCrAlY coatings were either Febased (FeCrA1Y) or Co-based (CoCrAlY) containing minor amounts of $\mathrm{Y}$. These were vapor deposited by an electron-beam process to a thickness of $\sim 4$ mils. The experimental coating, $\sim 4$ mils thick, was also applied by the electron-beam process. All of the vapor deposited coatings were given a subsequent diffusion treatment at $1925^{\circ} \mathrm{F}$.

Results on Rene' 80

\section{Effect of Exposure on Microstructural Changes}

The heat-treated condition of Rene' 80 contains approximately $47 \mathrm{~V} / 0 \gamma^{\prime}, 2 \mathrm{~V} / \mathrm{O} \mathrm{MC}$ (rich in Ti, W, and Mo) and very minor amounts of $\mathrm{M}_{23} \mathrm{C}_{6}$ and $\mathrm{M}_{3} \mathrm{~B}_{2}$. Figure 2 shows the carbide stability ranges in Rene' 80 , which are similar to those found in Rene' 77 or Rene' 100(1). Insofar as the phenomenon of tensile embrittlement is concerned, the most important consequence of high-temperature, long-time exposure lies in the appearance of $\mathrm{M}_{23} \mathrm{C}_{6}$ at the expense of $\mathrm{MC}$. This $\mathrm{MC} \rightarrow \mathrm{M}_{23} \mathrm{C}_{6}$ reaction occurs most readily at $1800^{\circ} \mathrm{F}$ and reverses its direction at higher temperatures. Within the stability range of $\mathrm{M}_{23} \mathrm{C}_{6}$, some $\mathrm{M}_{6} \mathrm{C}$ is also formed, which, however, is neither as abundant nor as influential as the $\mathrm{Cr}$-rich $\mathrm{M}_{23} \mathrm{C}_{6}$.

The $\mathrm{MC} \rightarrow \mathrm{M}_{23} \mathrm{C}_{6}$ reaction in $\mathrm{Ni}$-base superalloys is known to be accompanied by formation of the $\gamma^{\prime}$ phase. The overall reaction can be described as $\mathrm{MC}+\gamma \rightarrow \mathrm{M}_{23} \mathrm{C}_{6}+\gamma^{\prime}$. These microstructural changes in Rene' 80 under representative exposure conditions are illustrated in Figs. 3 and 4 . Fig. 3, top, shows vividly the increasing predominance 


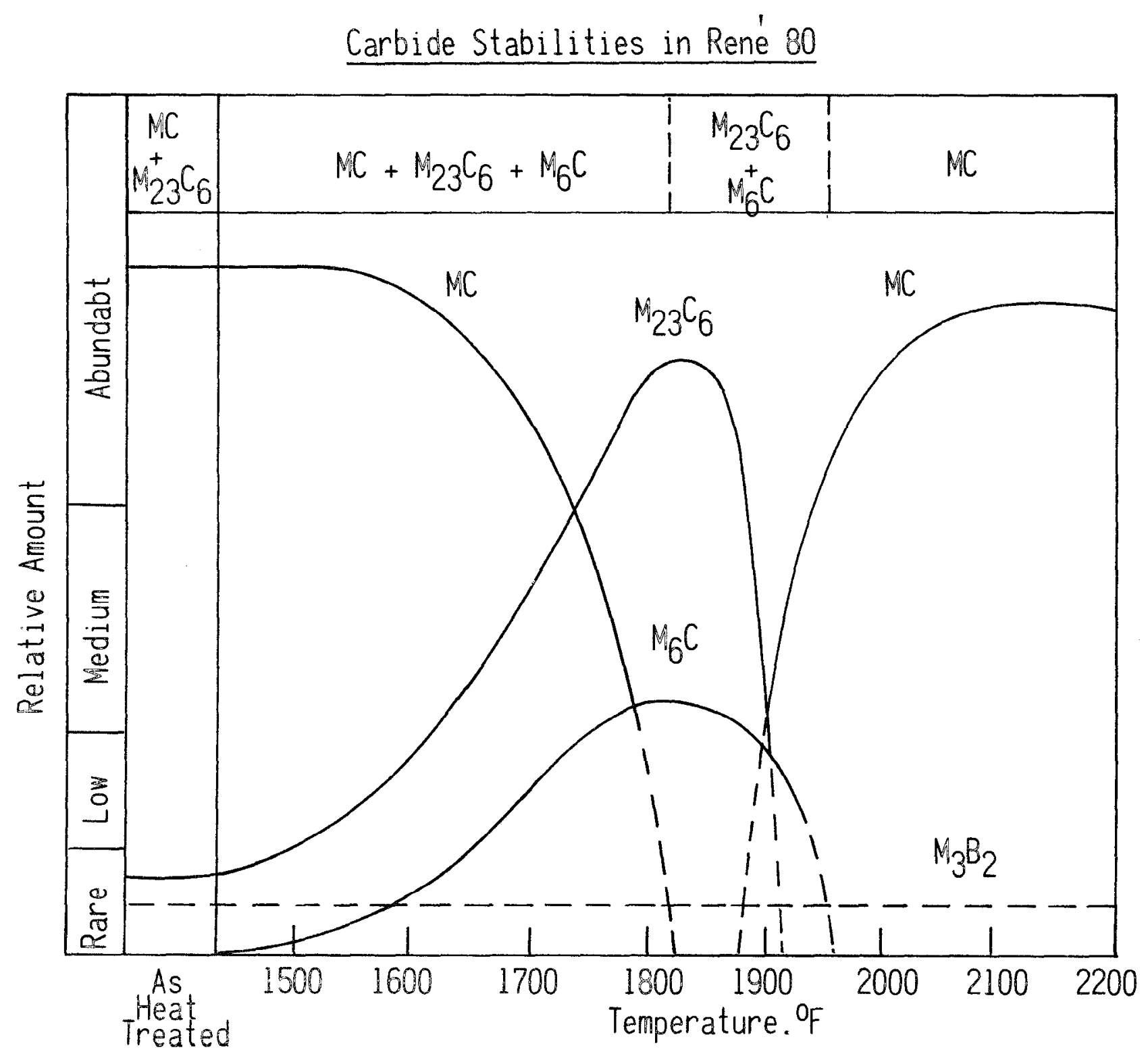

Figure 2. Carbide Stability Ranges in Rene' 80. 


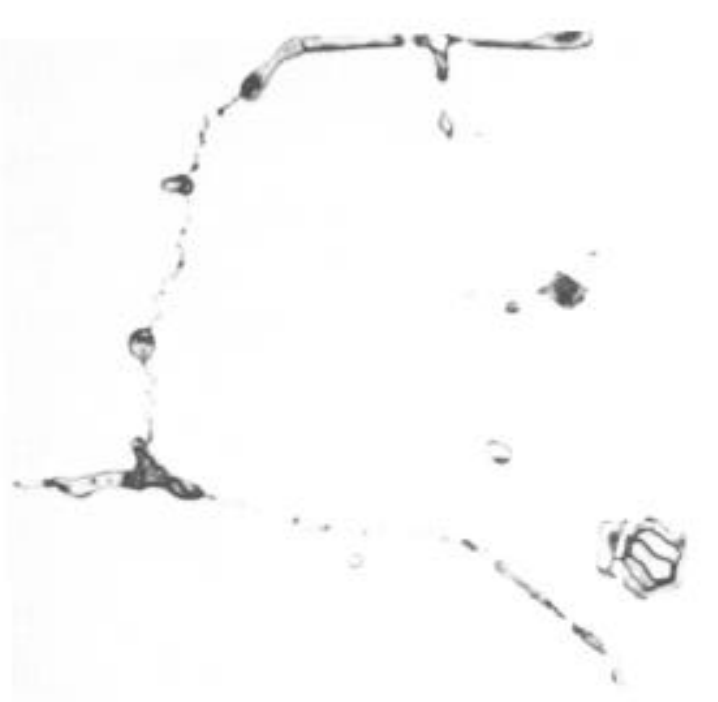

(A)

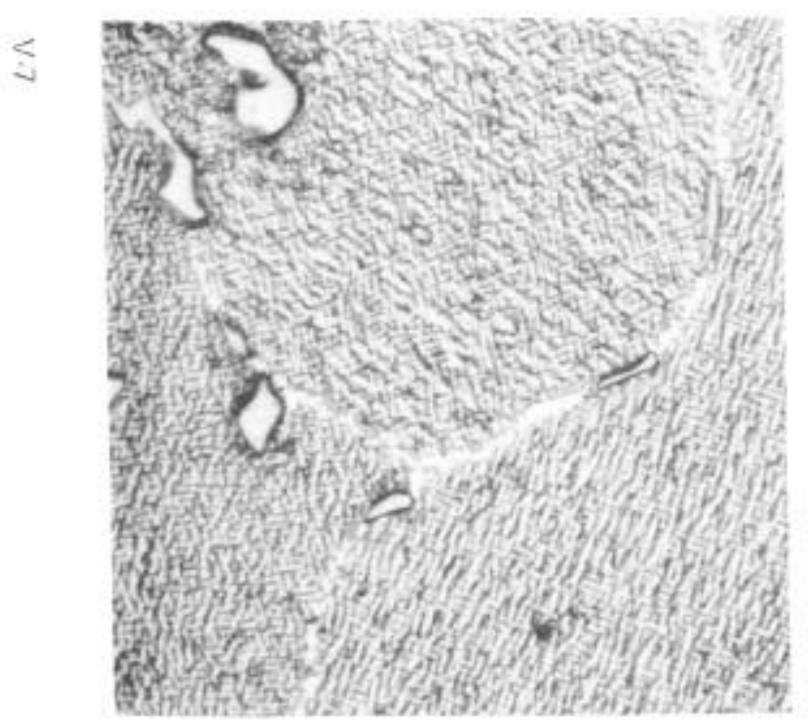

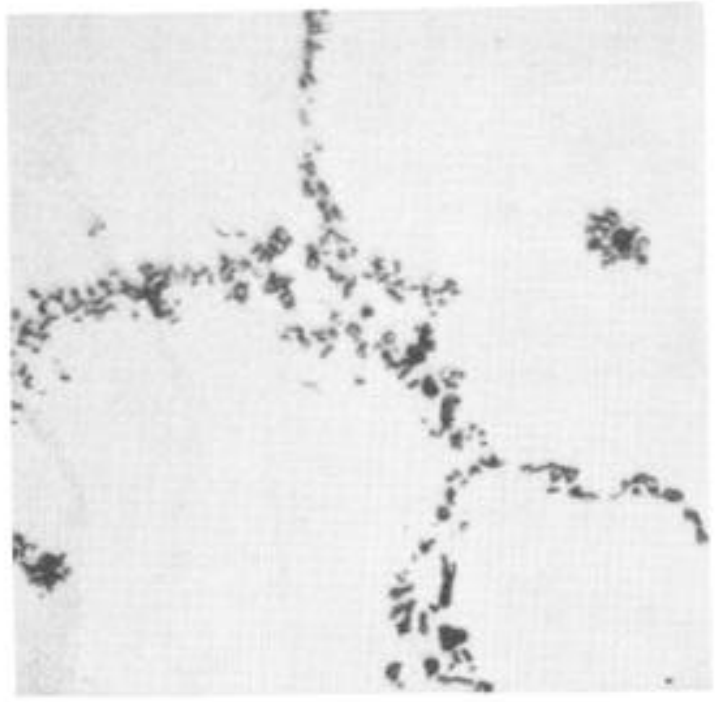

(B)

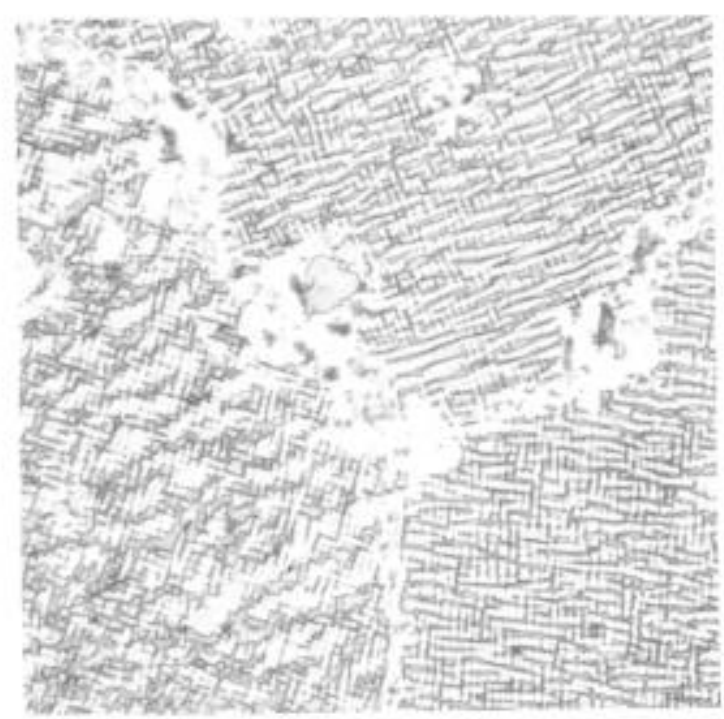

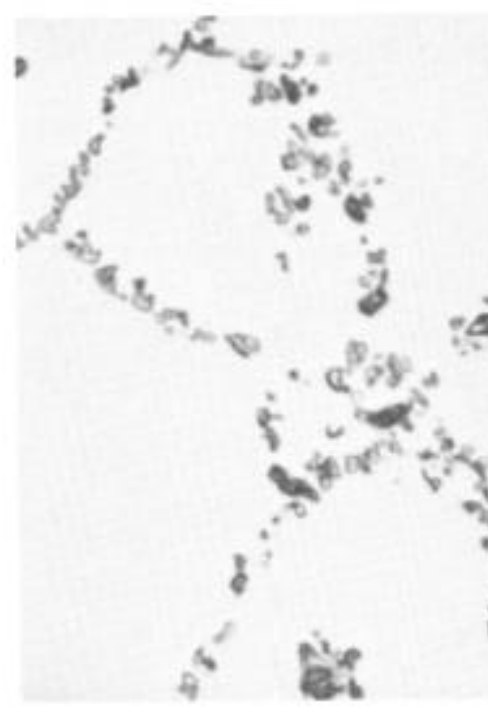

(C)

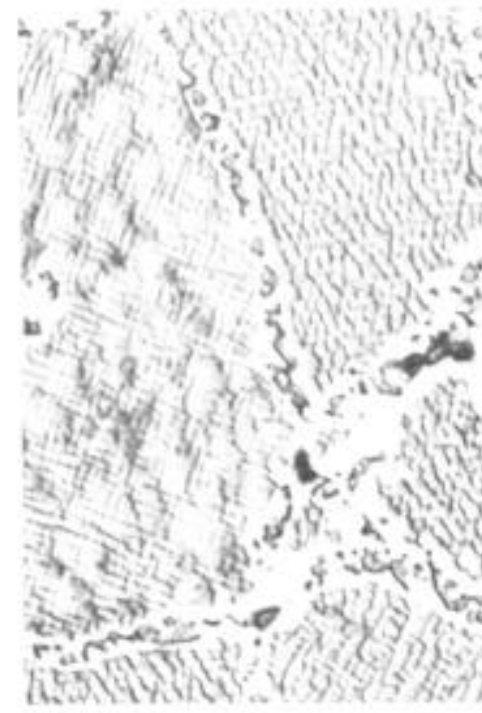

Figure 3. Microstructural Changes in Rene' 80 (A) As Heat Treated, (B) $1650^{\circ}$ $1125 \mathrm{Hr}$, and (C) $1800^{\circ} \mathrm{F} / 500 \mathrm{Hr}$. Top - Etched with Murakami's to Show Carbides. Bottom - Etched with Phosphoric Acid to Show Network. 1000X 


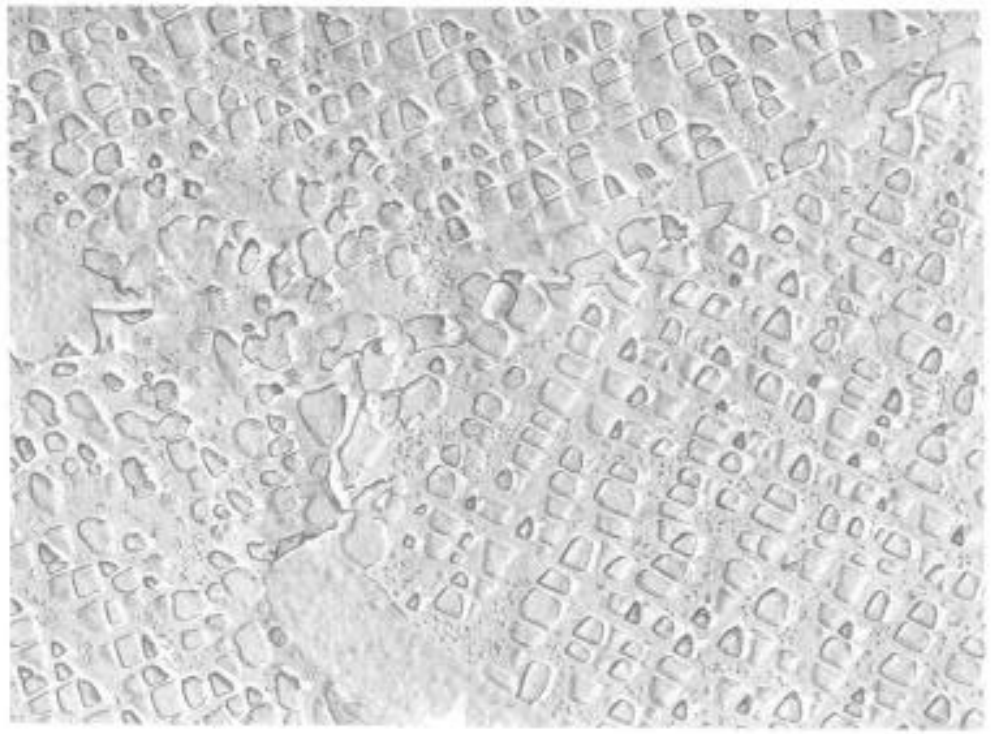

(A)

so

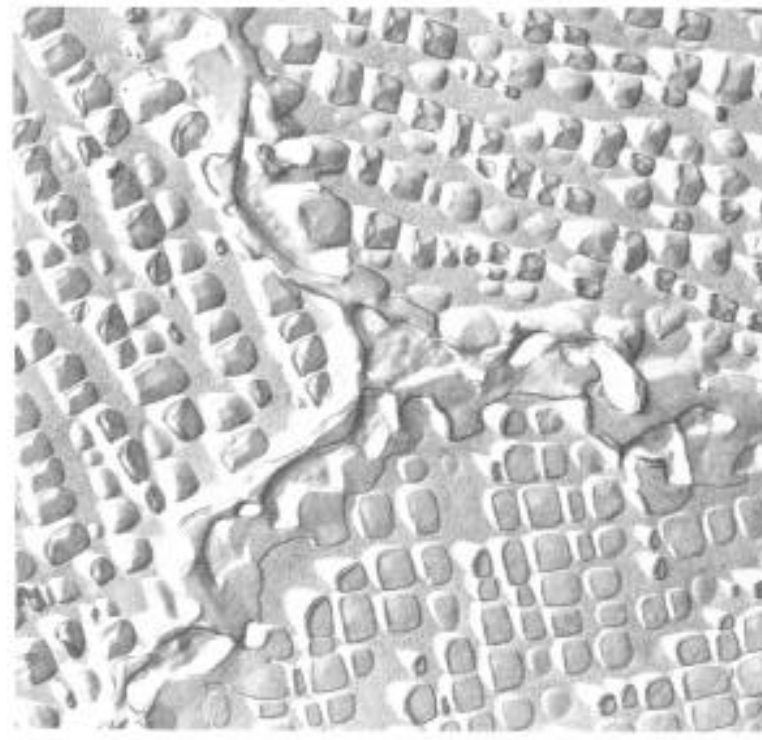

(B)

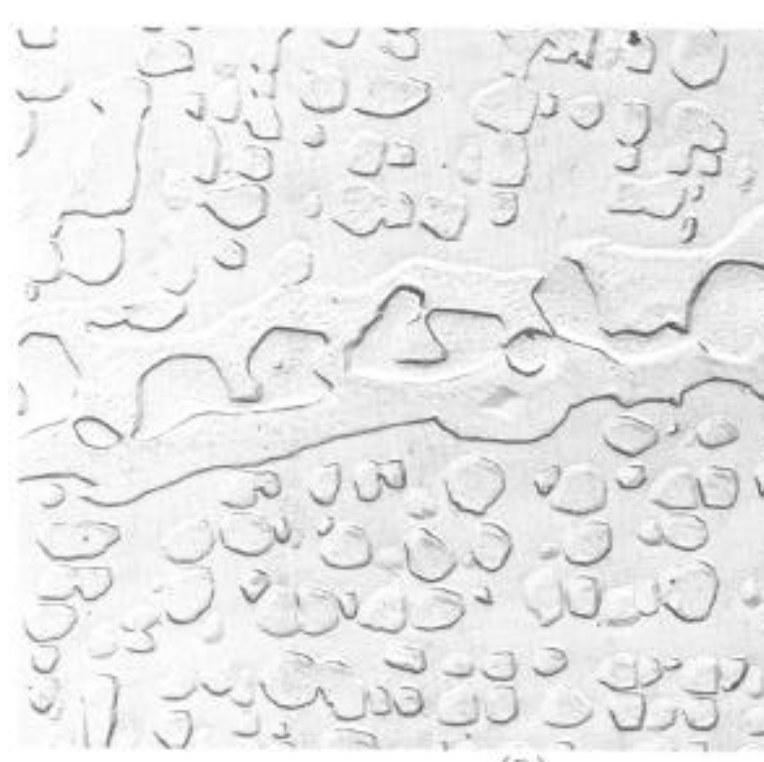

(D)

Figure 4. Electron micrographs of Rene' 80 . $200 \mathrm{Hr}$, (C) $1800^{\circ} \mathrm{F} / 200 \mathrm{Hr}$ and (D) $1800^{\circ} \mathrm{F} / 500 \mathrm{Hr}$. $5000 \mathrm{X}$

(B) 170 
of $\mathrm{M}_{23} \mathrm{C}_{6}$, particularly along the grain boundaries. The accompanying $\gamma^{*}$ formation, which eventually results in the light-etched grain-boundary network, is clearly delineated in Fig. 3 (bottom). Both the size of $\mathrm{M}_{23} \mathrm{C}_{6}$ particles and the width of the $\gamma^{\prime}$ network are seen to grow with exposure temperature and time (Fig. 4). Simultaneously, there is a gradual agglomeration of the intragranular $\gamma^{\prime}$ particles.

Effect of Exposure Atmospheres

Chronologically, the first scries of experiments consisted of comparing specimens exposed in air with those exposed in vacuum. The exposure was carried out for times up to 750 hours at $1800^{\circ} \mathrm{F}$, a temperature known to induce embrittlement readily. The exposed specimens were tensile tested in air at $1600^{\circ} \mathrm{F}$ under a nominal strain rate of $0.005 / \mathrm{min}$. Figure 5 shows tensile ductility in terms of reduction in area as a function of exposure time. (Identical trends were obtained by using elongation as criterion.) Included are data on directionally-solidified (D.S.) Rene' 80 , both monocrystalline and polycrystalline, exposed in air. The ovcrall results shown in Figure 5 are as striking as they are obvious. Conventionally-cast Rene' 80 exposed in air even for only 25 hours invariably had ductility reduced from about $25 \%$ to less than $3 \%$. In direct contrast, specimens exposed in vacuum up to the longest duration of 500 hours retained high ductility with equal consistency. The results on D.S. Rene' 80 are yet more interesting and informative. Thus, air exposure had no adverse effect on cluctility of the monocrystals and its effect on the columnar-grained specimens was highly directional. In the latter case, ductility was largely retained in the longitudinal direction, but was reduced to nil in the transverse direction.

Two major clues to the cause of tensile embrittlement emerged from the above results. The fact that ductility was not adversely affected in the as-heat-treated condition nor after vacuum exposure led to the inevitable conclusion that embrittlement involved both structural changes and increased sensitivity of these changes to hot air environment. Secondly, the behavior of D.S. materials indicated clearly that the environmental effect in question arose not from ordinary oxidation processes (such as scaling and alloy depletion), but from some subtle activities at the grain boundaries. The possibility of notch effect due to intergranular oxidation was discounted since this mode of attack normally does not occur in Rene' 80 during stress-free exposure(8) nor was it observed in the air-exposed specimens. In conjunction with the microstructural changes described previously, these considerations cast strong suspicion upon interactions of oxygen and/or nitrogen with the grain-boundary $\gamma^{\prime}$ network, which formed during exposure. As will be shown later, tensile fracture of exposed Rene' 80 was completely intergranular through the $\gamma^{\prime}$ network.

Surface Removal and Kinetics of Contamination

To further characterize the exposure effects, additional specimens air exposed at $1800^{\circ} \mathrm{F}$ were progressively centerless ground prior to tensile test. Tests were again conducted in air at $1600^{\circ} \mathrm{F}$, and a strain rate of $0.005 / \mathrm{min}$. Figure 6 shows variations of tensile ductility with amount of surface removal. Ignoring for the time being the discrepancies shown for the longer exposures, ductility is seen to recover after certain amounts of surface removal, in some cases reaching levels 


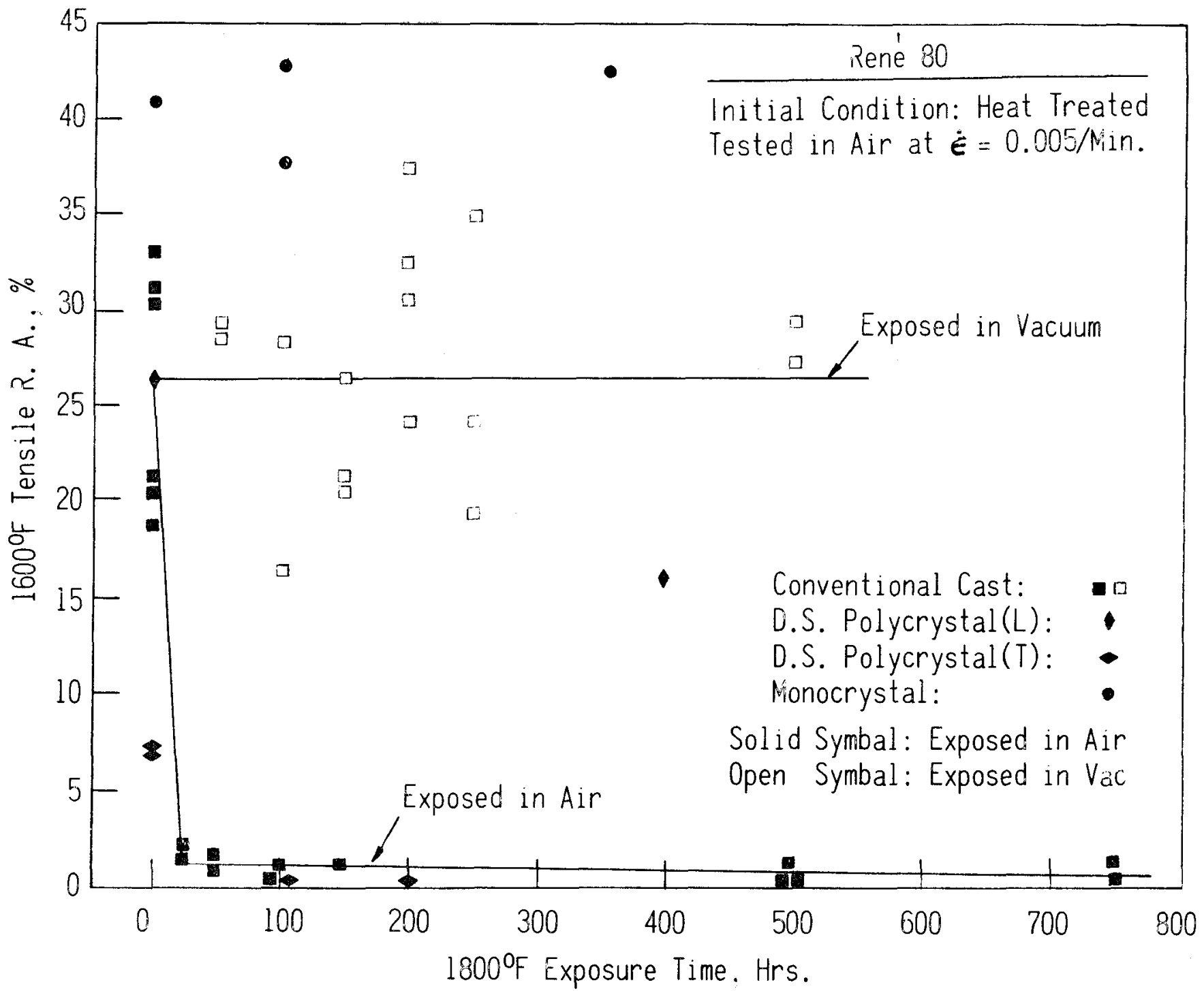

Figure 5. Effect of $1800^{\circ} \mathrm{F}$ Exposure Atmosphere and Time on Tensile Ductility of Rene' 80 . 


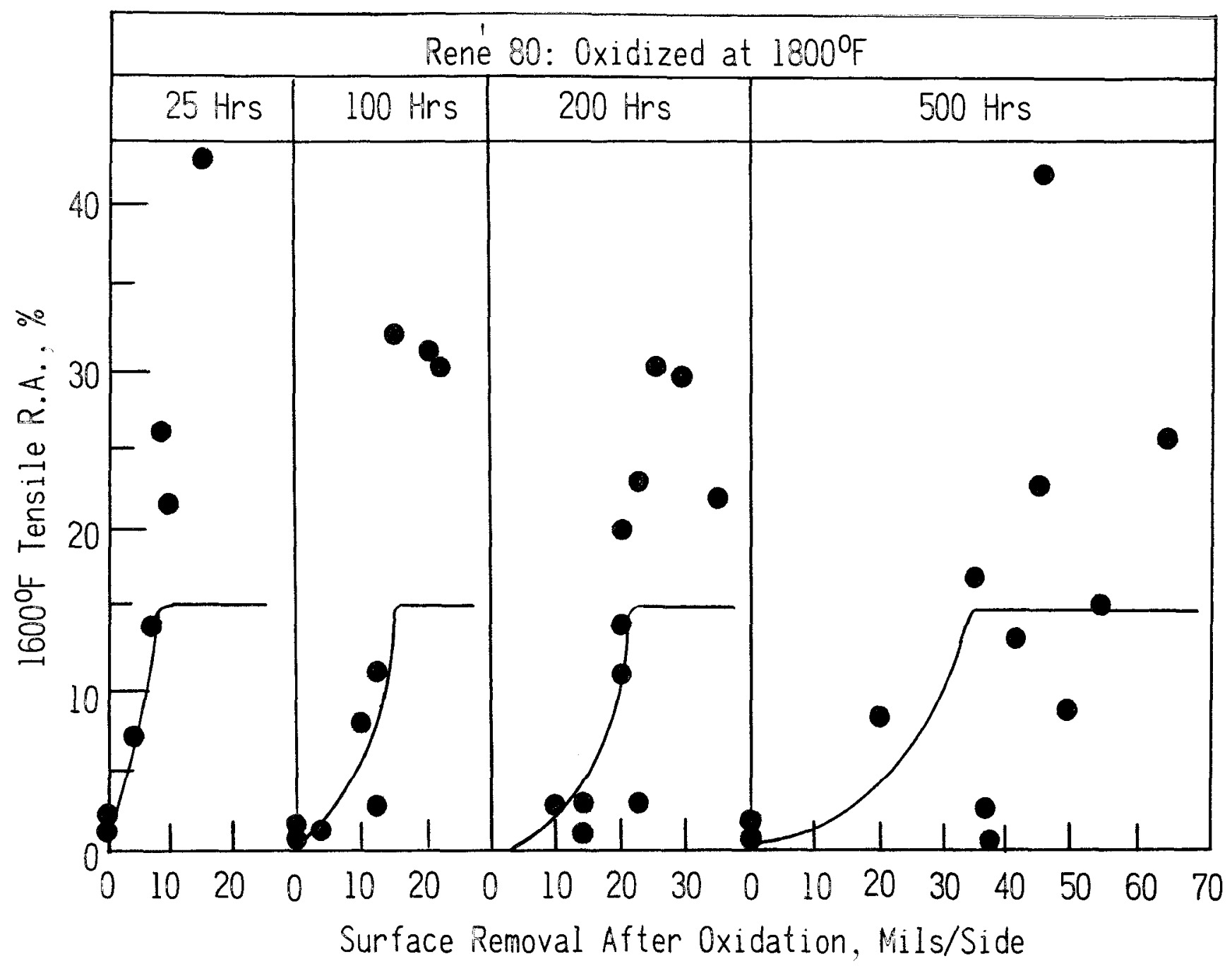

Figure 6. Effect of Surface Removal on Tensile Ductility of Rene' 80 after $1800^{\circ} \mathrm{F}$ Exposure in Air. 
exceeding those of the unexposed condition. Using 15\% R.A. as an arbitrary criterion, the minimum amount of surface removal required for ductility recovery increased with duration of exposure, being approximately $8,15,22.5$, and $35 \mathrm{mils} / \mathrm{side}$ for exposures of 25, 100, 200 , and 500 hours, respectively. This type of behavior clearly portrays time-dependent contamination, apparently along the grain boundaries. As will be discussed later, both nitrogen and oxygen probably participated in the inward diffusion. Since monocrystals were not affected by air exposure, it appeared reasonable to conclude that the grain-boundary $Y^{\prime}$ network, rather than the matrix $Y$ phase, was the host through which the embrittlement-related contamination occurred. This conclusion was supported by subsequent findings on dynamic interactions described later.

Equating the minimum amount of surface removal to maximum depth of contamination and again using $15 \%$ R.A. as the ductility criterion, the time dependency of contamination is shown in Fig. 7. Included in this figure are the maximum depths of surface oxidation comprising outer scale, internal oxidation, and alloy depletion. Both contamination and oxidation appear to increase parabolically with time. The respective relationships were $\mathrm{X}^{2}=2.45 \mathrm{t}$ and $\mathrm{Y}^{2}=0.08 \mathrm{t}$ in which $\mathrm{X}$ is the depth of conlaminalion in $\mathrm{mils} / \mathrm{side}$ and $\mathrm{Y}$, deplh of oxidalion in mils/side; $\mathrm{t}$, time of exposure in hours and 2.45 and 0.08 , the respective rate constants in $\mathrm{mils} 2 /$ hour. Thus, under the exposure conditions used, the depth of contamination was about 5 to 6 times greater than the depth of oxidation.

As indicated in Figures 6 and 7 , discrepancies were found after the longer exposures in that the specimens remained brittle regardless of the amount of surface removal. These discrepancies were traced to improper machining which left a cold-worked surface susceptible to crack initiation. As will be shown later, surface cracking exposed the $\gamma^{\prime}$ network to the testing environment, thus allowing dynamic interactions and embrittlement. Crack initiation of a poorly ground surface could be reduced by gentle hand polish or by vacuum stress relief at $1800^{\circ} \mathrm{F}$.

The kinetics of contamination were further investigated by air exposure at $1650^{\circ}, 1700^{\circ}$, and $1900^{\circ} \mathrm{F}$. The effect of surface removal is depicted in Figure 8 from which the respective rate constants of 0.40 , 0.78 , and $8.0 \mathrm{mil} / \mathrm{s} / \mathrm{hr}$ were determined. In conjunction with the $1800^{\circ} \mathrm{F}$ data, the rate constants conformed to a simple Arrhenius relationship shown in Fig. 9. A least-square fit resulted in the straight line whose equation is $\mathrm{K}=1.82 \times 10^{3} \mathrm{exp}(-67,000 / \mathrm{RT})$, where $\mathrm{K}$ is contamination rate constant in $\mathrm{cm} 2 / \mathrm{sec}$; $T$ is temperature in ${ }^{\circ} \mathrm{K}$; and $R$ is gas constant. The contamination phenomenon thus appears to be associated with an activation energy of $67.0 \mathrm{kcal} / \mathrm{mole}$.

Strain-Rate Effects and Dynamic Interactions

The intermetallic compound $\mathrm{Ni}_{3} \mathrm{Al}$ was known to have high strainrate sensitivity(9). Monocrystals of Ni3Al were reported to exhibit ductility minimum in the neighborhood of $1600^{\circ} \mathrm{F}(10)$. Since the $\gamma^{\prime}$ network was heavily implicated in the embrittlement of Rene' 80 , the effect of strain rate was next investigated. Tensile tests using nominal strain rates of $0.005,0.05$, and 0.5 per min. were conducted at $1600 \mathrm{~F}$ in air on both heat-treated specimens and specimens which had 


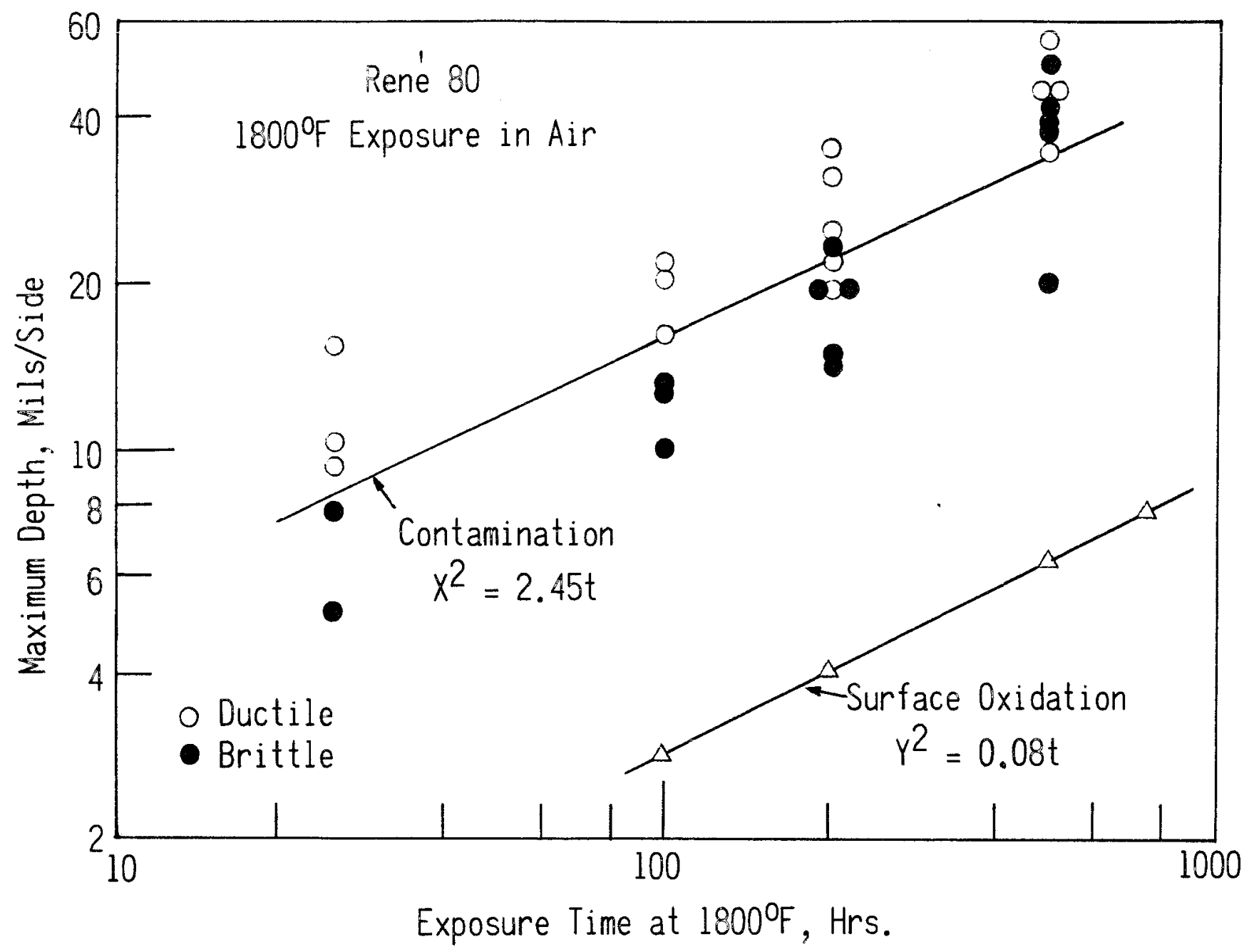

Figure 7. Effect of $1800^{\circ} \mathrm{F}$, Air Exposure on Contamination and External Oxidation of Rene' 80 . 


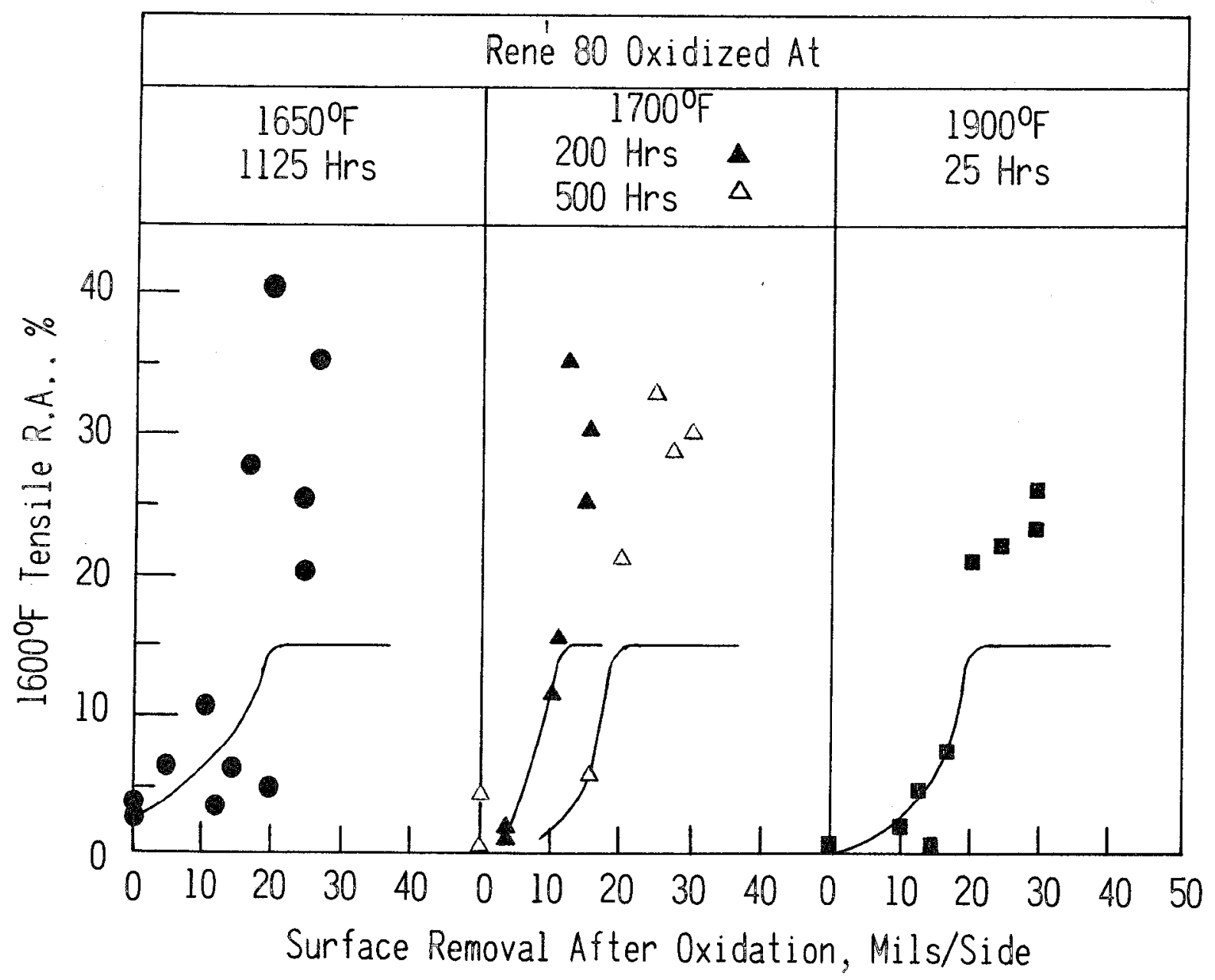

Figure 8. Effect of Surface Removal on Tensilc Ductility of Rene' 80 after Air Exposure at $1650^{\circ} \mathrm{F}, 1700^{\circ} \mathrm{F}$, and $1900^{\circ} \mathrm{F} . \quad(\dot{\epsilon}=0.005 / \mathrm{min}$. 


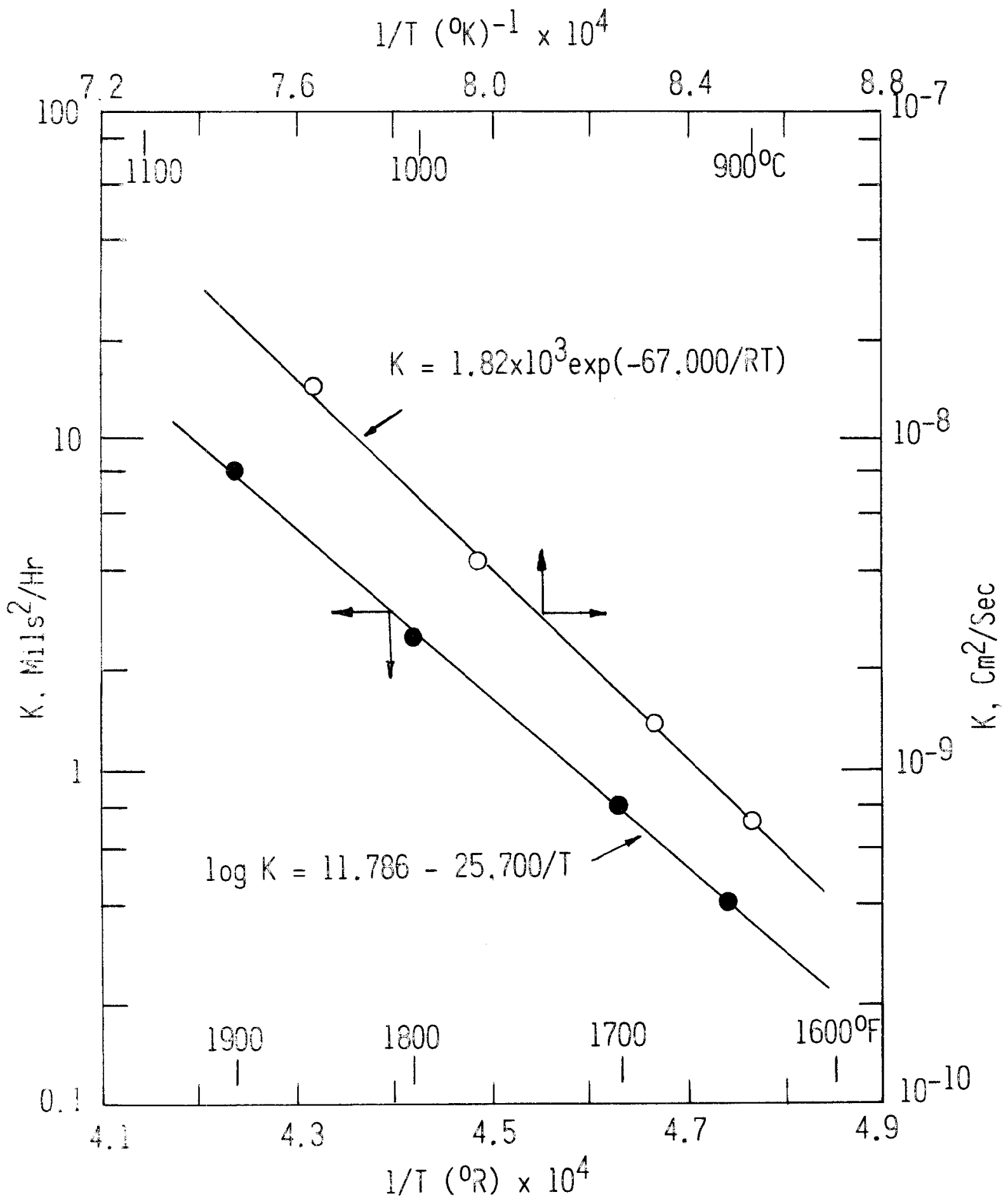

Figure 9. Temperature Dependence of Contamination Rate in Rene' 80. 
bcen vacuum cxposed at $1800 \mathrm{~F}$ to generate the $\gamma^{\prime}$ network without contamination. Both types of specimens showed similar increase in strength with strain rate. They differed, however, markedly in the effect of strain rate on ductility. Figure 10 shows that whereas the heat-treated condition remained ductile throughout the entire range of strain rates, the exposed condition became severely embrittled except at the lowest strain rates of $0.005 / \mathrm{min}$. These results at first glance seemed to suggest an inlrinsic brittleness of $\mathrm{Ni} 3_{\mathrm{Al}}$ as a consequence of its high strain-rate sensitivity. To ascertain whether this was indeed the case, the tensile tests were repeated in vacuum. Results of the vacuum tests are included in Fig. 10 for comparison. These proved to be most enlightening in uncovering hitherto unsuspected complications. Unlike in air tests, both the heat-treated and the exposed specimens now retained high ductility up to the highest strain rate investigated. Note in Fig. 10 that the strain-rate effects in either environment were highly consistent and reproducible. It was thus unequivocally clear that the embrittlement of the exposed condition in air under high strain rates was environmental, rather than intrinsic, in nature. This conclusion, in turn, made it apparent that the strain-rate effect on ductility must lie in altering the location of crack initiation and propagation. Specifically, while failure of a ductile material in normal tensile tests is known to initiate by internal cracking, high strain rates may either shift crack initiation to the surface or cause simultaneous interior and surface cracks, thereby allowing direct interactions with the testing environment. Figure 11 shows that regardless of testing environment and strain-rates, tensile fracture of Rene' 80 at 1600F was either predominantly (as heat treated) or completely (exposed) intergranular. Note in Fig. IlC that intergranular failure of the exposed specimens passed through the network along the $\gamma^{\prime} / \gamma^{\prime}$ interface decorated with fine $\mathrm{M}_{23} \mathrm{C}_{6}$ carbides. Figure 12 shows a heat-treated specimen tensile tested in air at $\dot{\varepsilon}=0.5 / \mathrm{min}$. to $\sim 10 \%$ elongation and retested to failure at $\varepsilon=0.005 / \mathrm{min}$. Surface cracks (a large one indicated by arrow) were indeed observed. Final failure upon retesting proceeded from the large surface crack, accompanied by a significant amount of additional plastic deformation. Since cracking was predominantly intergranular in the heat-treated condition, the additional deformation was consistent with the behavior of monocrystals in indicating that neither the $\gamma$ matrix nor the $\gamma / \gamma$ grain boundary was as vulnerable to the environmental effects as the $\gamma^{\prime}$ network which formed upon exposure. Similar evidence on the effect of strain rate was found on exposed specimens tested in air. Figure 13, for instance, shows an internal crack after about $10 \%$ elongation at a strain rate of $0.005 / \mathrm{min}$. and a surface crack on another specimen which failed after $0.8 \%$ elongation at a strain rate of $0.5 / \mathrm{min}$. In both cases, cracking was completely intergranular.

The results described above established beyond any reasonable doubt that in addition to contamination by inward diffusion of oxygen and nitrogen, the grain-boundary $y^{\prime}$ network was further susceptible to instantaneous interactions with the interstitials. These two major modes of $Y^{\prime}$ network embrittlement in a hot-air environment are referred to as "static" and "dynamic" interactions, respectively.

Further evidence of, and the interplay between, the two modes of interactions is given in Figures 14 and 15. The absence of grain boundaries and hence $\gamma^{\prime}$ network rendered Rene' 80 monocrystals immune to both types of environmental effects (Fig. 14). This is to be contrasted to the behavior of (a) conventionally-cast Rene' 80 exposed 


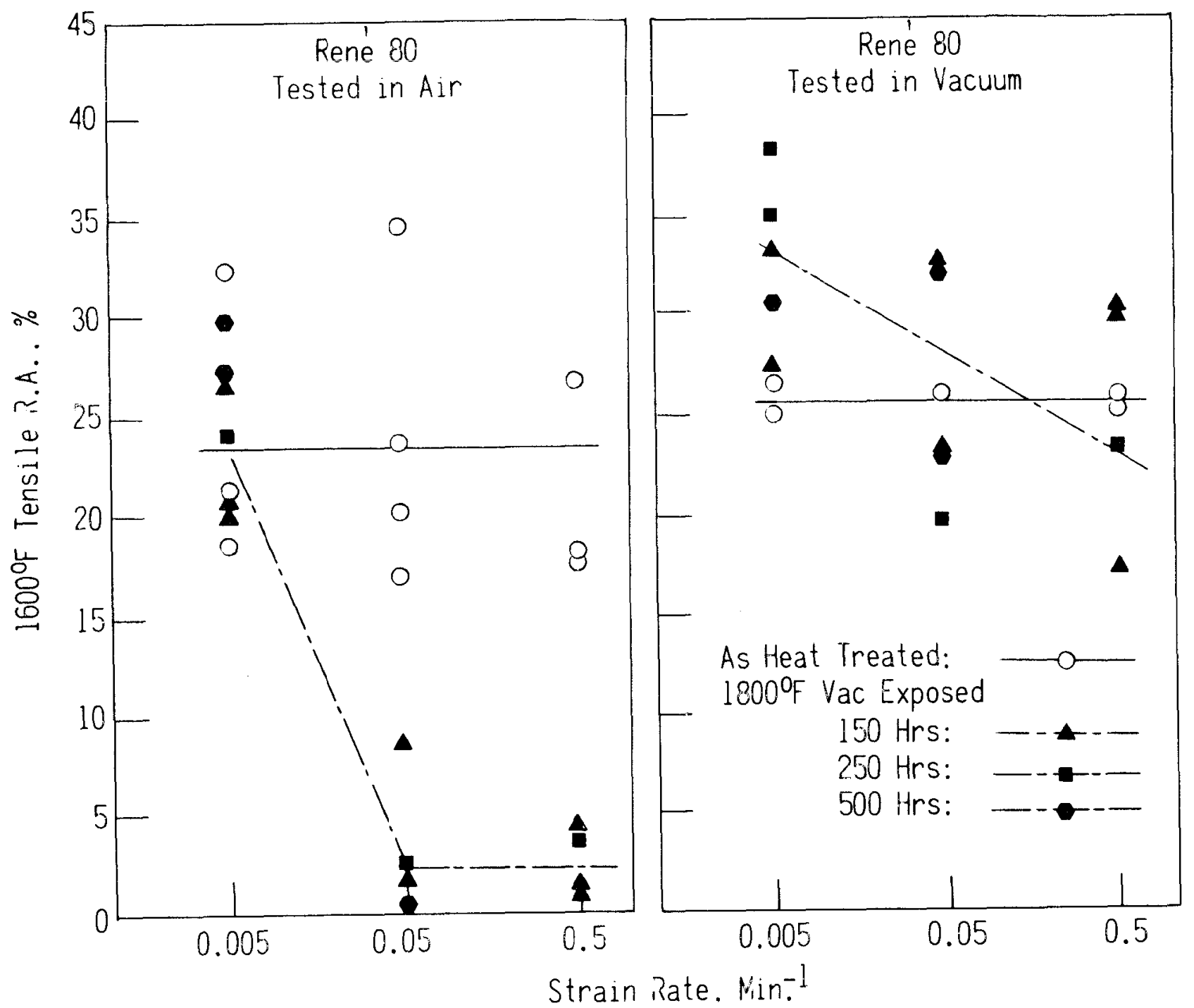

Figure 10. Effects of Testing Atmosphere and Strain Rate on Tensile Ductility of Rene' 80 after $1800^{\circ} \mathrm{F}$ Exposure. 


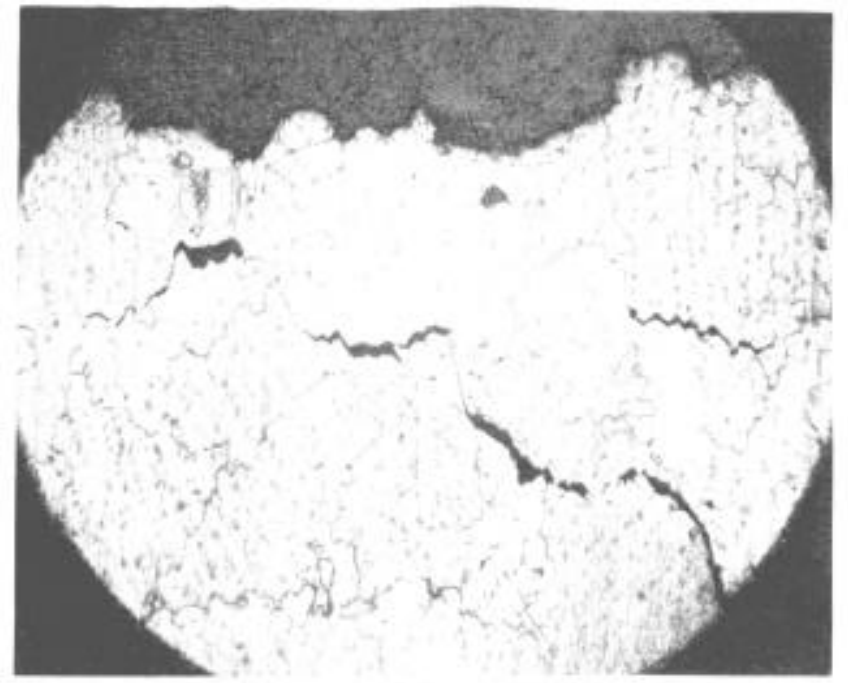

(A)

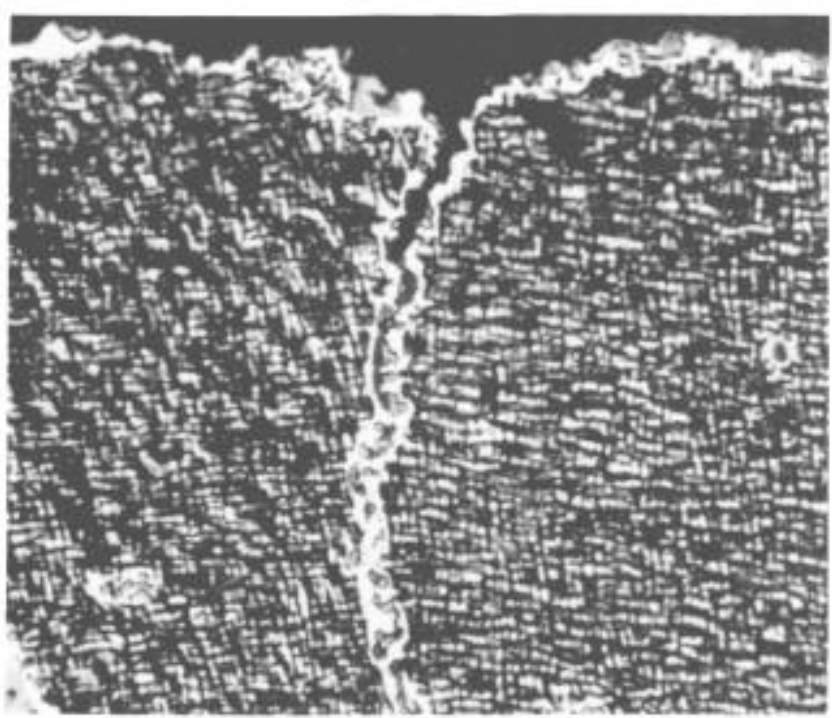

(C)

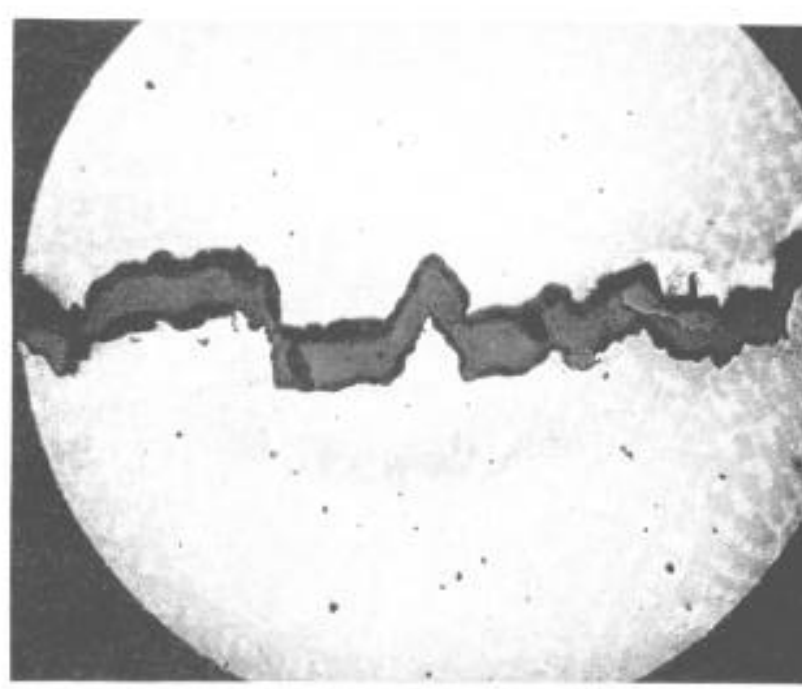

(B)

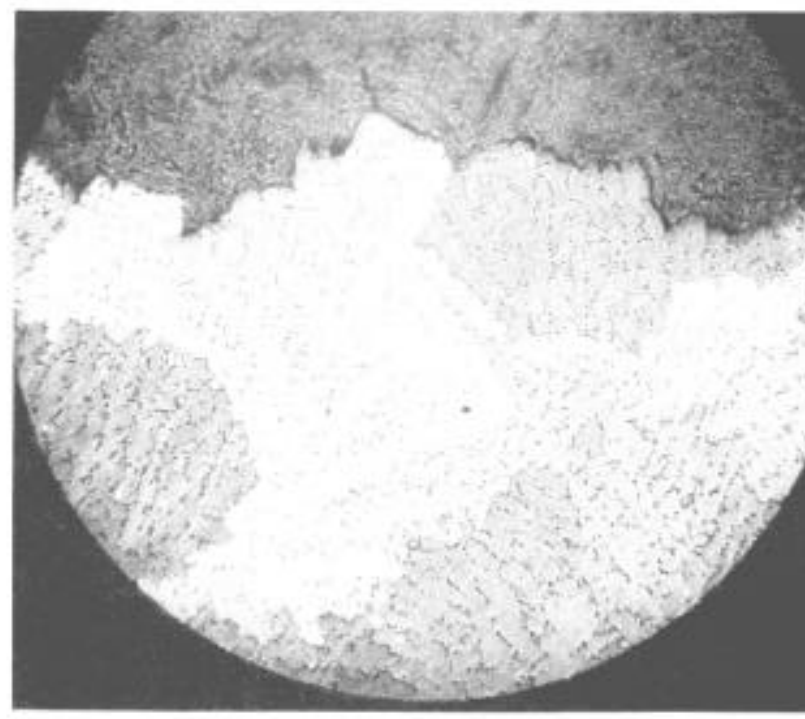

(D)

Figure 11. Tensile Fractures of Rene' 80 at $1600^{\circ} \mathrm{F}$. (A) As Heąt Treated. $\varepsilon=0.005 / \mathrm{Min}$. in Air. 25X, (B) As Heat Treated. $\varepsilon=0.5 / \mathrm{Min}$. in Air. 25X, (C) After $1800^{\circ} \mathrm{F}$ Exposure. $\dot{e}=0.005 / \mathrm{Min}$. in Vacuu $1000 \mathrm{X}$, and (D) After $1800^{\circ} \mathrm{F}$ Exposure. $\dot{\varepsilon}-0.5 / \mathrm{Min}$. in Vacuum. 2 


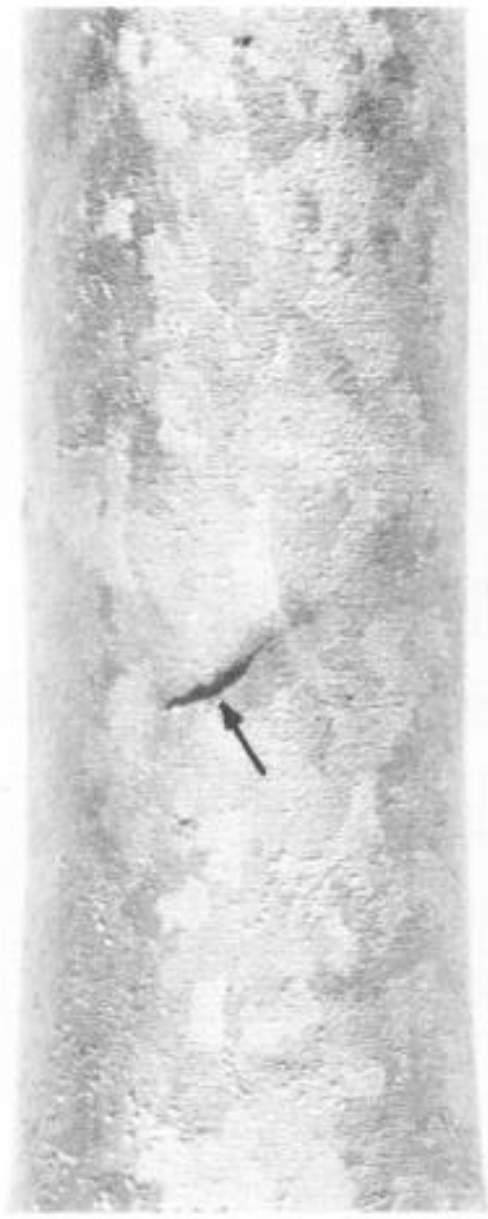

(A)

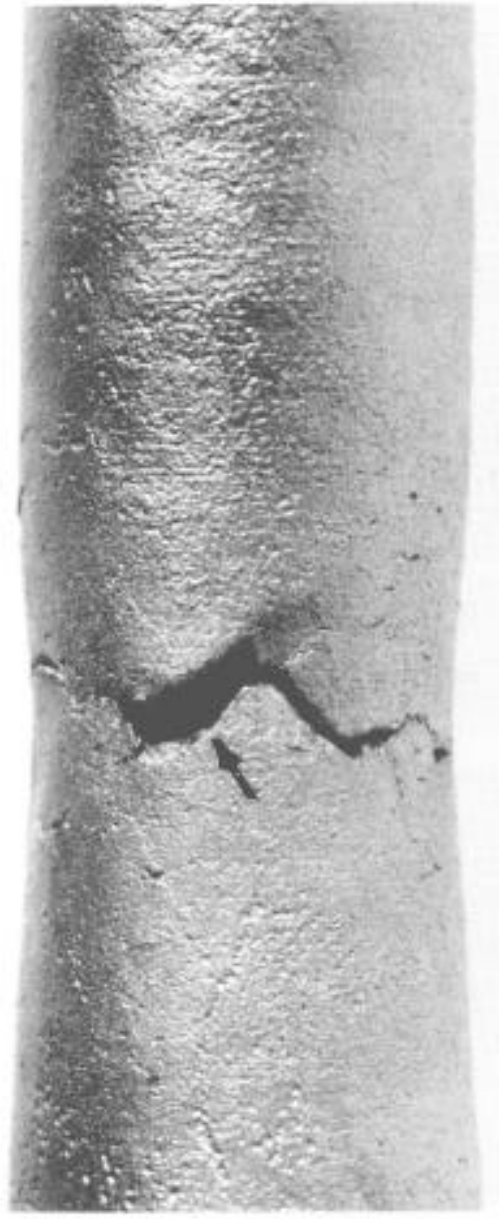

(B)

Figure 12. As Heat Treated Rene' 80 Tested in Air (A) Tested at $\dot{\varepsilon}=0.5 / \mathrm{Min}$. Test Interrupted after $10 \% \mathrm{El}$. and $9 \% \mathrm{R} . \mathrm{A}$. (B) Retested at $\dot{\varepsilon}-0.005 / \mathrm{Min}$. to Failure. $13.4 \% \mathrm{El}$. and $18.4 \%$ R.A. 


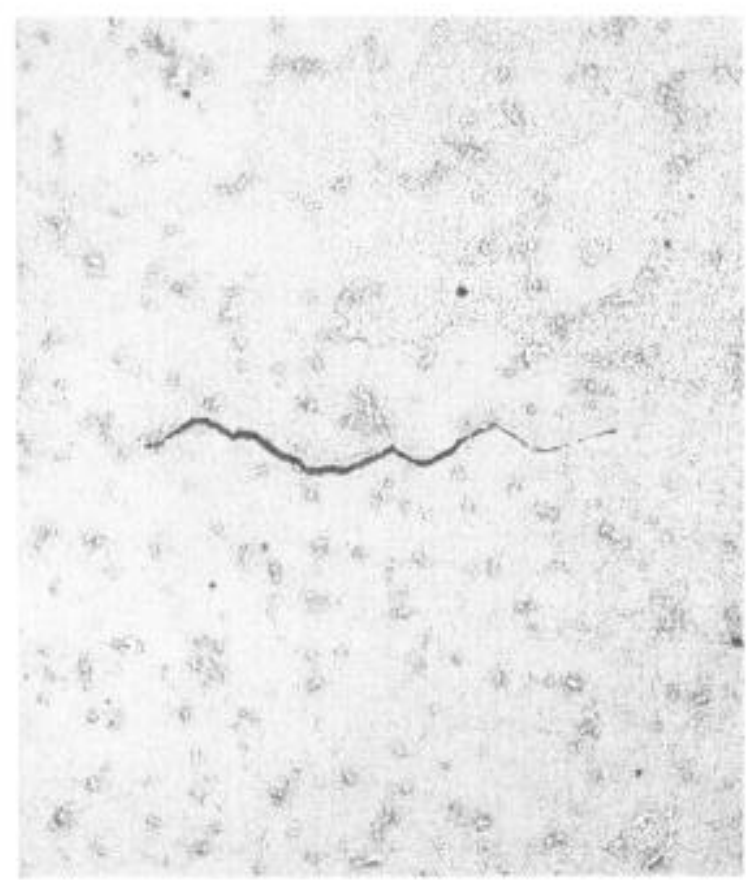

(A)

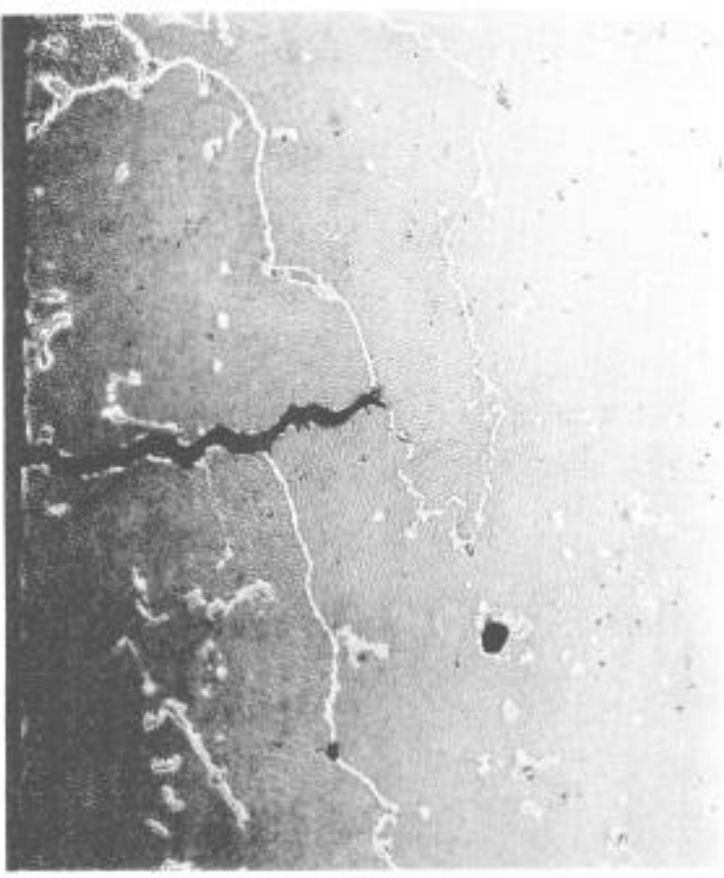

(B)

Figure 13. Rene' 80 Exposed at $1800^{\circ} \mathrm{F}$ and Tensile Tested at $1600^{\circ} \mathrm{F}$. (A) Internal Crack after $10 \% \mathrm{El}$. at $0.005 / \mathrm{Min} .75 \mathrm{X}$. (B) Surface Crack after $0.8 \%$ E1. at $0.5 / \mathrm{Min}$. 250X. 


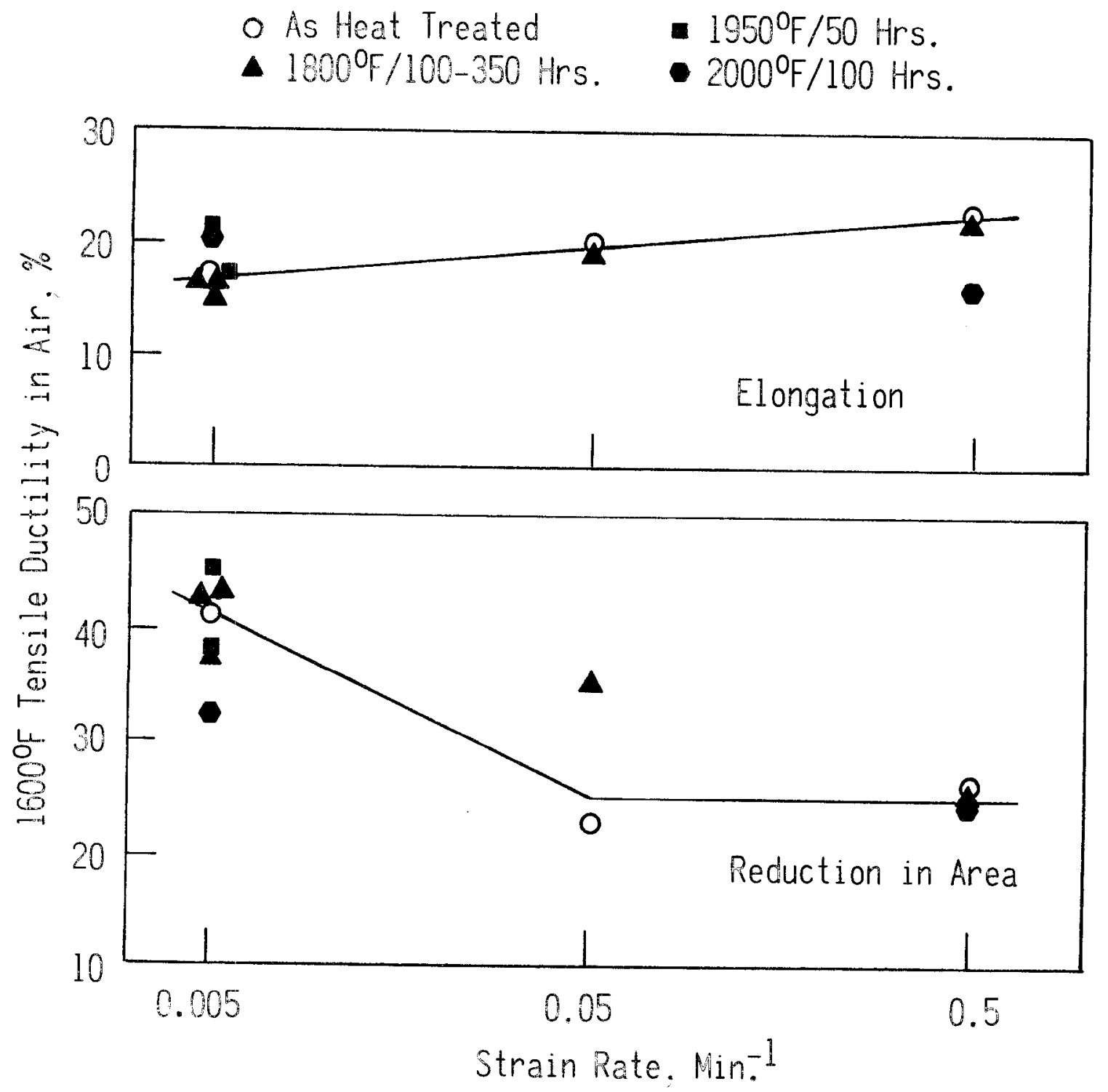

Figure 14. Effect of oxidation on Tensile Ductility in Air of Rene' 80 Monocrystals. 


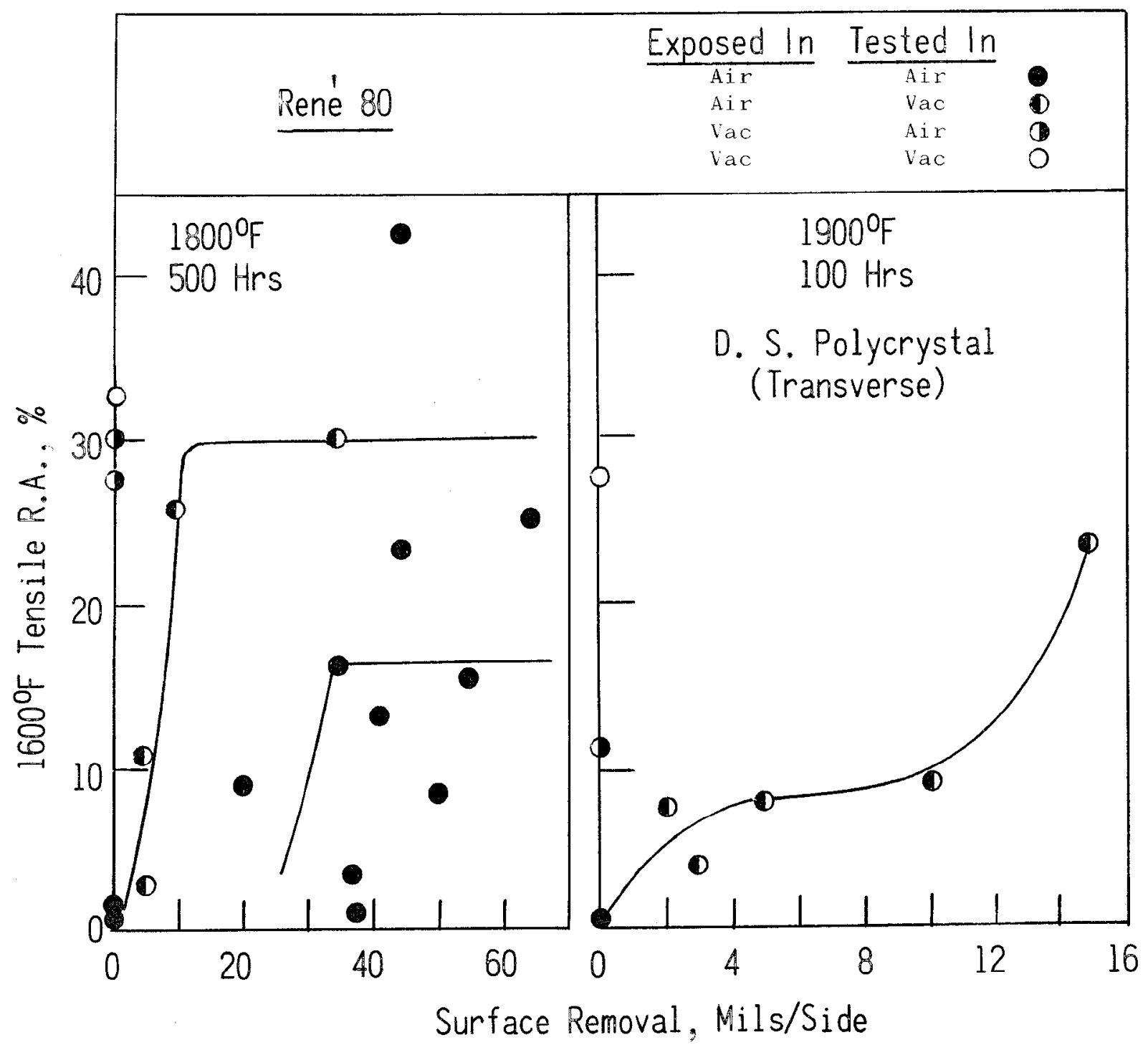

Figure 15. Effects of Exposure and Testing Atmospheres on Ductility of (A) Conventionally Cast Rene' 80 after Exposure at $1800^{\circ} \mathrm{F} / 500 \mathrm{Hr}$ and (B) Directionally solidified Rene' 80 in Transverse Direction after Exposure at $1900^{\circ} \mathrm{F} / 100 \mathrm{Hr} . \quad(\dot{\varepsilon}=0.005 / \mathrm{Min}$. 
at $1800 \mathrm{~F} / 500$ hours and (b) D.S. polycrystalline Rene' 80 , in the transverse direction, after exposure at 1900F/100 hours, shown in Fig. 15. In both cases, high ductility was always maintained when both exposure and testing were conducted in vacuum. Testing in air of noncontaminated material (either by vacuum exposure or by sufficient surface removal) also resulted in high ductility unless dynamic interactions intervened through surface cracking caused by insufficient surface removal, poor surface preparation, or unfavorably-oriented (i. e. transverse) grain boundaries. Finally, note the effect of contamination or static interactions on air-exposed specimens which were tested in vacuum after various amounts of surface removal. Embrittlement was not eliminated by testing in vacuum when the contaminated zone was insufficiently removed. On the other hand, in the absence of dynamic interactions, it was possible to regain high ductility with less surface removal than required by testing in air.

\section{Effect of Protective Coatings}

Since tensile embrittlement resulted from environmental effects, it should be amenable to prevention by protective coatings. This expectation was initially confirmed by the application of codep, an aluminide coating of approximately 1.5 to 2 mils thick. Figure 16 shows that under strain rate of $0.005 / \mathrm{min}$., Codep-coated Rene' 80 was not embrittled after $1800 \mathrm{~F} / 200 \mathrm{hr}$ exposure in air. The coated specimens, however, lost their ductility under higher strain rates. This embrittling effect was readily explained and metallographically confirmed by the occurrance of surface cracking under high strain rates. The results suggested strongly that improved protection could be provided by coatings having a combination of greater thickness and higher ductility. On this basis, additional specimens coated with 4-mil thick FeCrAIY, CoCrAlY, and an experimental coating were tested after $1800 \mathrm{~F} / 200$ hour exposure in air. The test results and cracking characteristics are shown, respectively, in Figures 16 and 17 , in comparison with Codep. As expected, ductility was not retained by CoCrAlY which was relatively brittle owing to the large amounts of CoAl in a CoCrAl matrix, thus allowing rapid crack propagation through the entire thickness. The FeCrA1Y coating appeared to be erratic and did not prove to be as protective as expected. The deficiency was traced in part to sputtering defects and in part to the columnargrained coating structure which facilitated surface crack propagation. Note in Figure 17B that subsurface cracks also formed readily in the diffusion zone. Those inhorent drawbacks of FeCrAlY coating were minimized or eliminated in the experimental coating with considerably improved results. 


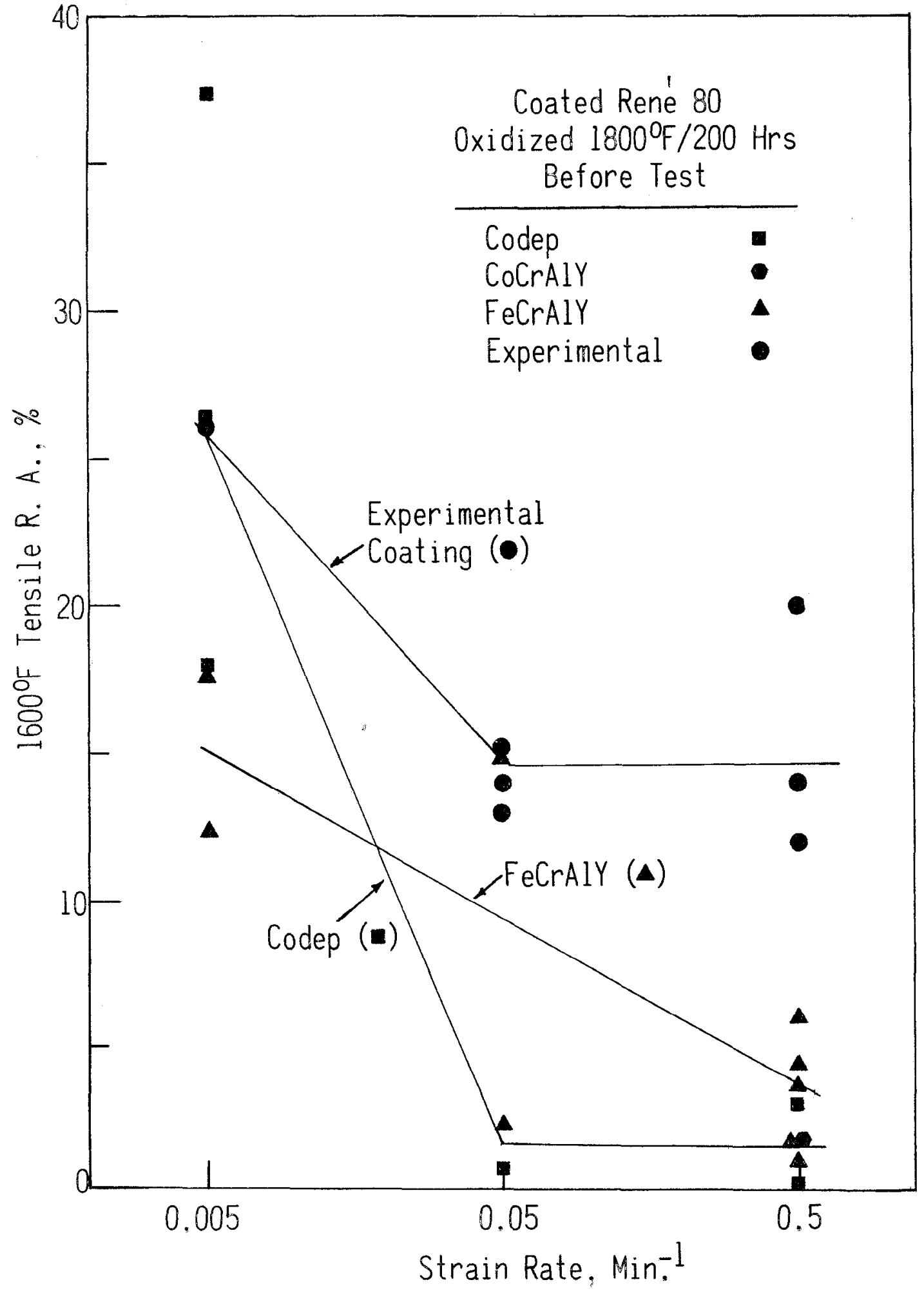

Figure 16. Effect of Strain Rate on Tensile Ductility in Air of Rene' 80 with Various Coatings. 


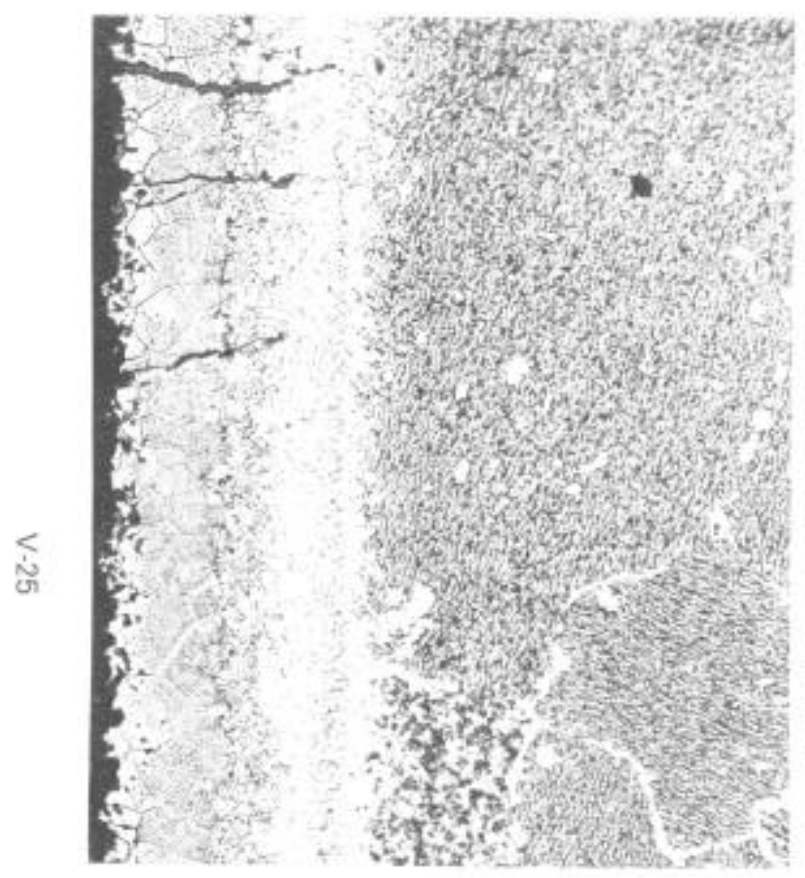

A. Codep-Coated 250x
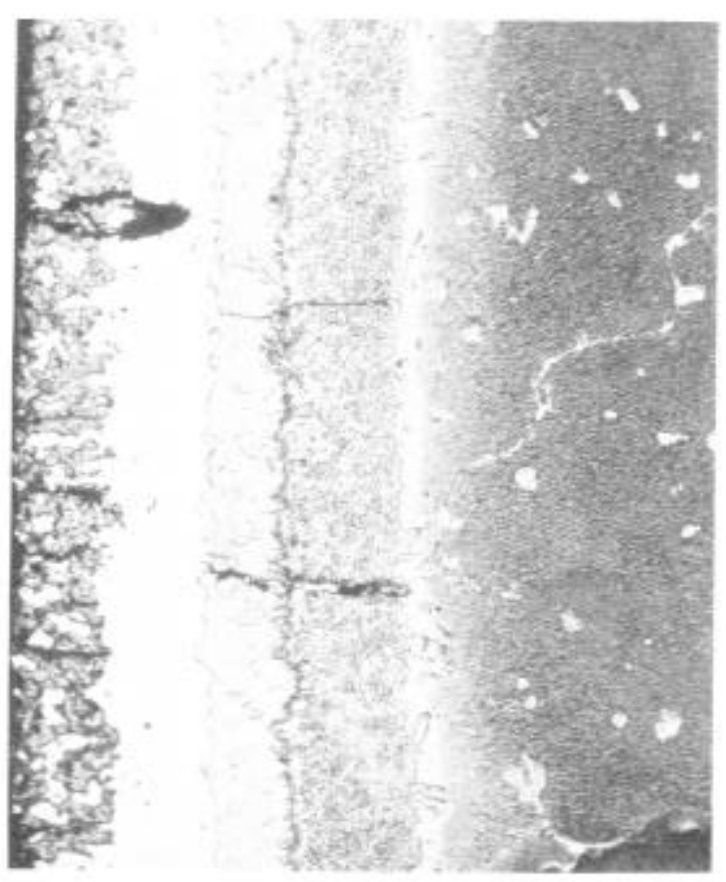

B, FeCrAlY-Coated 150X
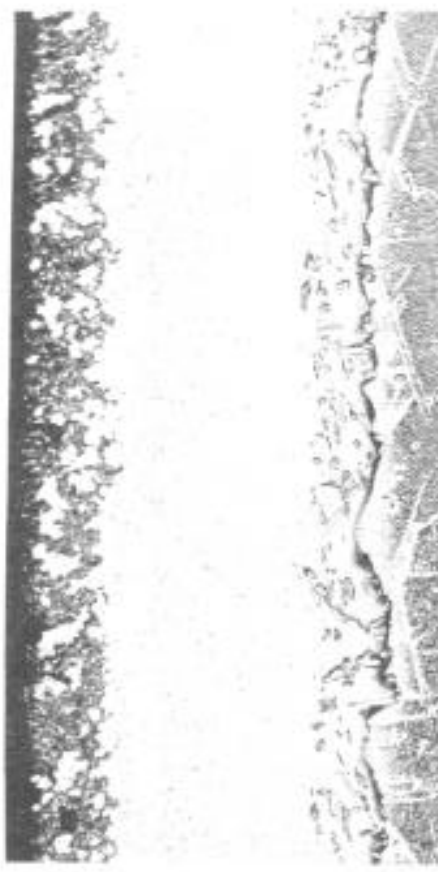

C. Experimental Coa

Figure 17. Cracking Characteristics in Coatings on Rene' 80 after Air Exposure at $1800^{\circ} \mathrm{F} / 200 \mathrm{Hr}$ and Tensile Tested at $1600^{\circ} \mathrm{F}$ in $\mathrm{A}$ under High Strain Rates. 
Results on Rene' 77 and Rene' 100

Once the relationships between $\gamma^{\prime}$ network and cnvironmental interactions had been uncovered, it became apparent that tensile embrittlement would not be unique to Rene' 80 but should be common to all $\mathrm{Ni}$-base alloys undergoing similar structural changes upon exposure. Confirmatory work was conducted on Rene' 77 and Rene' 100 which, by virtue of compositional differences, were known to have significant differences in volume fraction of $\gamma^{\prime}$ and in the extent of carbide reactions. Initial study carried out on Heat $L$ of Rene' 77 gave the results shown in Figure 18. In spite of some scatter, the $1600 \mathrm{~F}$ tensile ductility is seen to be degraded by $1800 F$ exposure in air, the effect becoming more severe with increases in exposure time and strain rate. Figure 19 shows additional data on Heats $L$ and $M$. Some differences in ductility existed between the two heats in the as-heattreated condition. Both heats, however, suffered embrittlement after exposure, especially when tested under high strain rates. Finally, Figure 20 illustrates the combined effects of exposure atmosphere, testing atmosphere, and strain rate. Compared with the heat-troated condition which remained ductile under all testing conditions, the ductility of Rene' 77 after the $1800 \mathrm{~F} / 500 \mathrm{hr}$ exposure was clearly both environment and strain-rate dependent, being much lower when both exposure and testing were carried out in air.

While Rene' 77 was indeed also susceptible to tensile embrittlement, the effect was not quite as pronounced as in Rene' 80 . Thus, air exposure for $100-200 \mathrm{hr}$ at $1800 \mathrm{~F}$ resulted in little change in ductility under slow strain rates and even the most severe exposure and testing conditions did not reduce the ductility to less than 5\% R.A. Further, Rene' 77 also appeared to be far less affected by dynamic interactions, as evidenced by its ability to retain high ductility in air under high strain rates after exposure in vacuum (Fig. 20)。As shown by the microstructural changes in Fig. 21, the higher tolerances for environmental interactions are correlatable to a lesser propensity toward continuous grain-boundary $\gamma^{\prime}$ network formation which, in turn, appears to be a consequence of the much lower carbon content $(0.07 \%)$ and hence less extensive $\mathrm{MC}+\gamma \rightarrow \mathrm{M}_{23} \mathrm{C}_{6}+\gamma^{\prime}$ reaction in Rene' 77 than in Rene' $80(0.17 \% \mathrm{C})$. The total volume fraction of $\gamma^{\prime}$ in Rene' 77 has been variously estimated to be $0.38(11)$ or $0.49(12)$, as compared with 0.47 in Rene' $80(12)$. This discrepancy in $\gamma^{\prime}$ volume traction probably is not as significant as the fact that the intragranular $\gamma^{\prime}$ particles in Rene' 77 were not as finely dispersed nor as stable as those in Rene' 80. The resulting lower strength may have made it possible for Rene' 77 to accommodate more plastic deformation in the matrix $\gamma$ phase prior to intergranular failure, thus contributing to ductility retention. In this respect, it may be noted that the propensity toward surface crack initiation and propagation (and hence susceptibility to dynamic environmental interactions) in Rene' 77 after exposure was likely to have also been moderated by the less continuous $\gamma^{\prime}$ network as well as the more deformable $\gamma$ matrix.

In contrast to Rene' 77 , Rene' 100 represented the opposite case of having a greater sensitivity to environmental effects than Rene' 80 . Figure 22 shows that unlike the other two alloys, even the as-heattreated condition of Rene' 100 suffered from dynamic interactions, exhibiting only half as much ductility in air as in vacuum. After air 


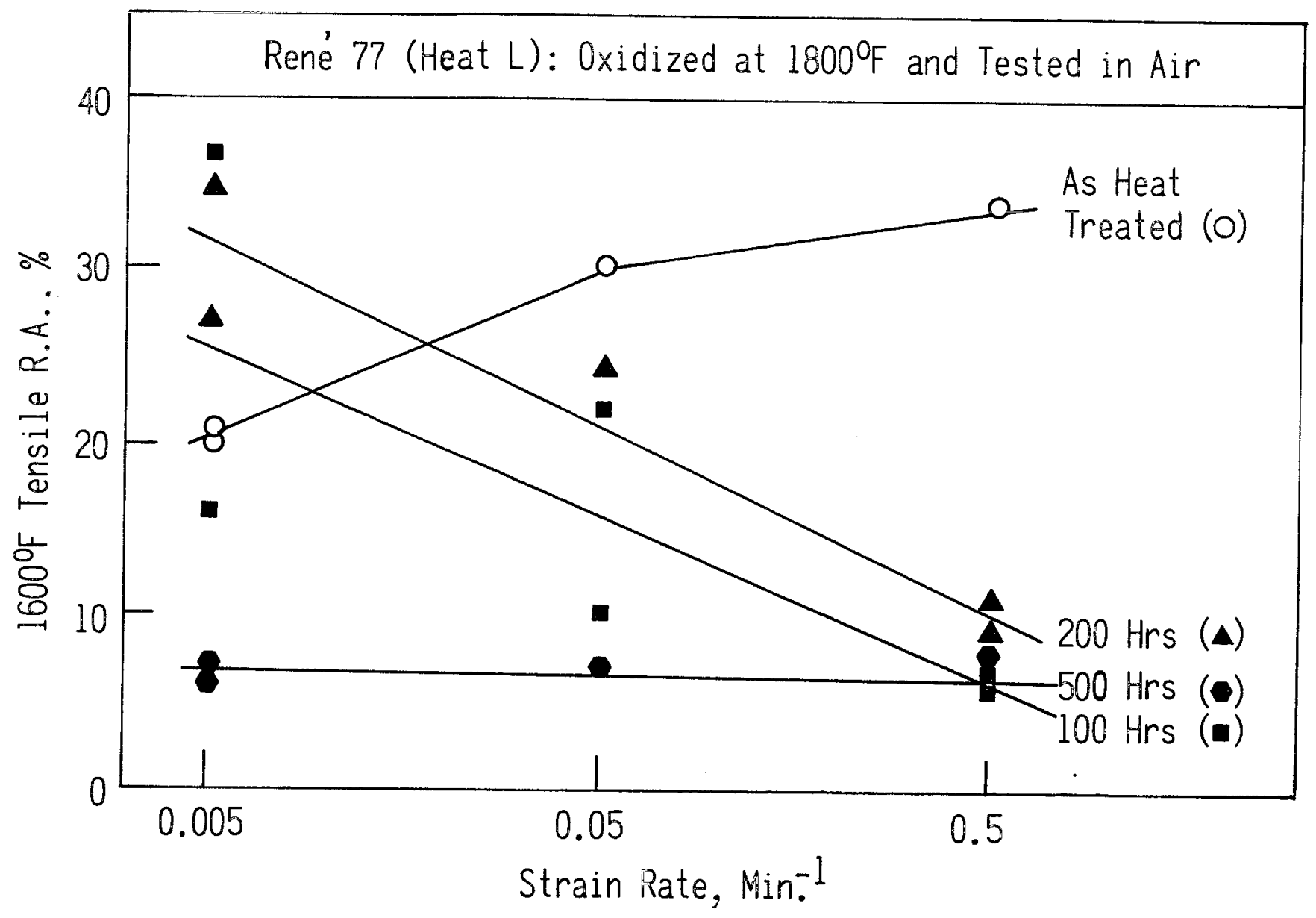

Figure 18. Effect of $1800^{\circ} \mathrm{F}$ oxidation on Tensile Ductility of Rene' 77 , 


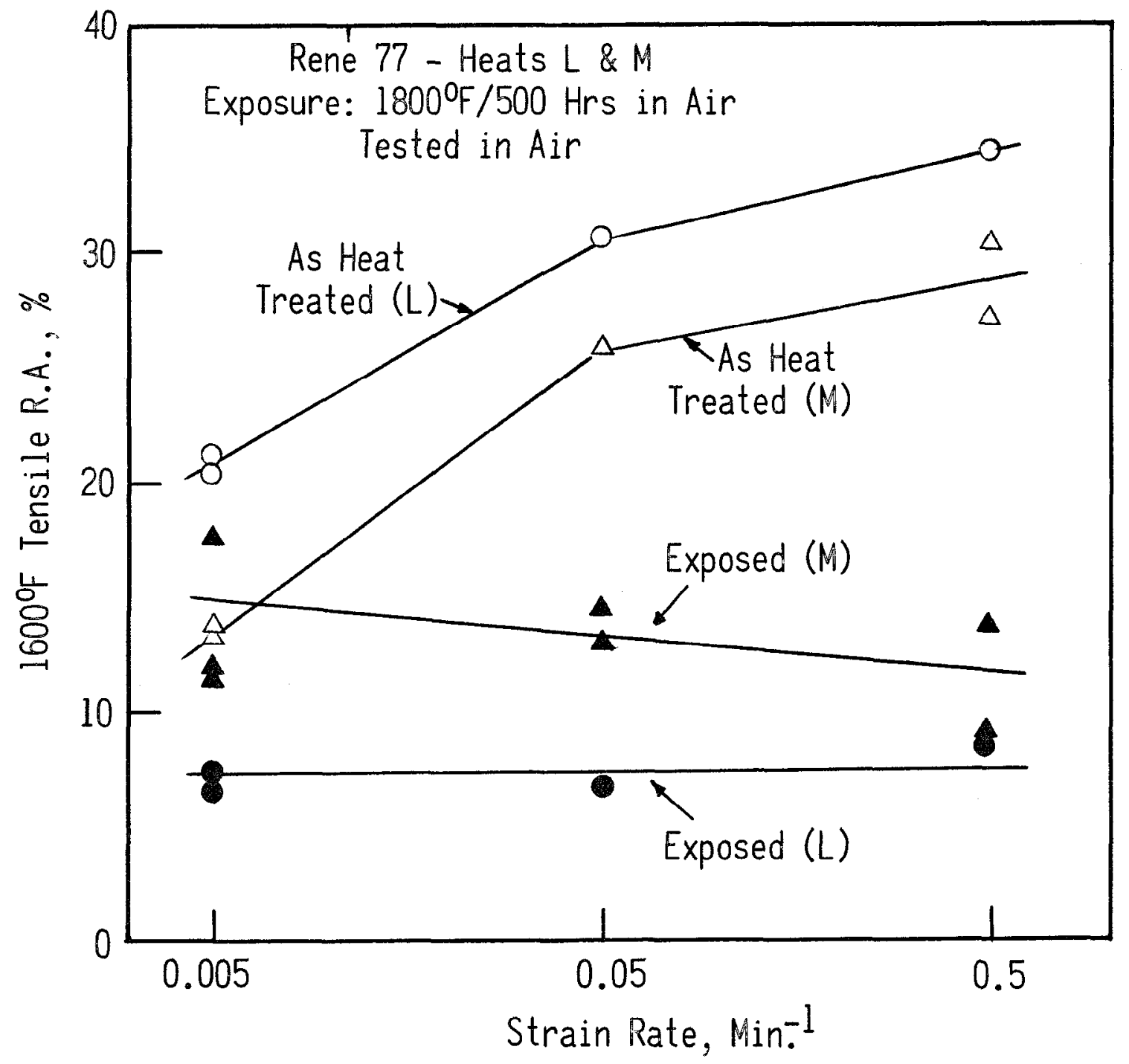

Figure 19. Effect of $1800^{\circ} \mathrm{F} / 500 \mathrm{Hr}$ oxidation on Tensile Ductility of Rene' 77 , Heats $L$ and $M$. 


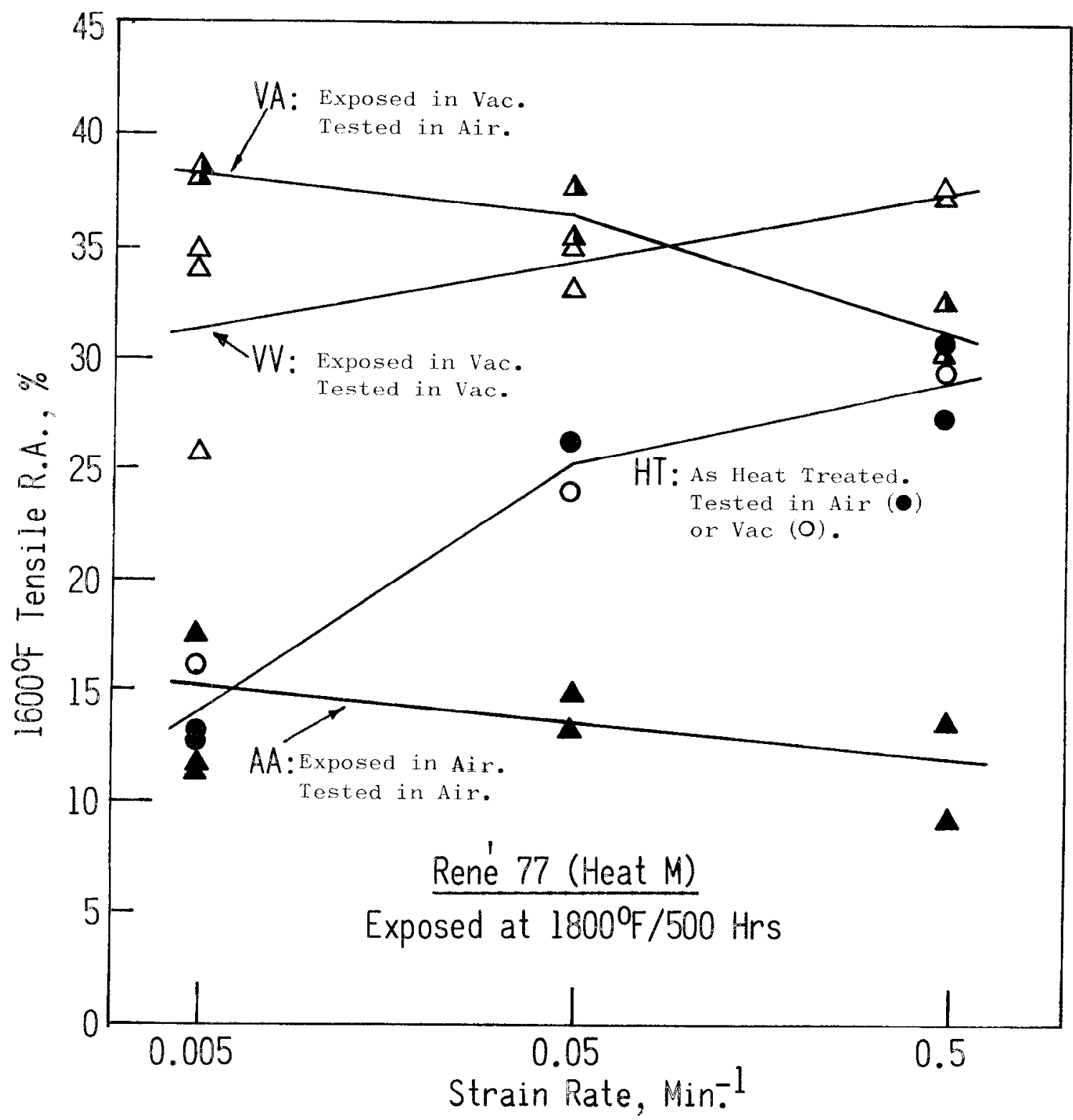

Figure 20. Combined Effects of Exposure Atmosphere, Testing Atmosphere and Strain Rate on Tensile Ductilily of Rene' 77 . 

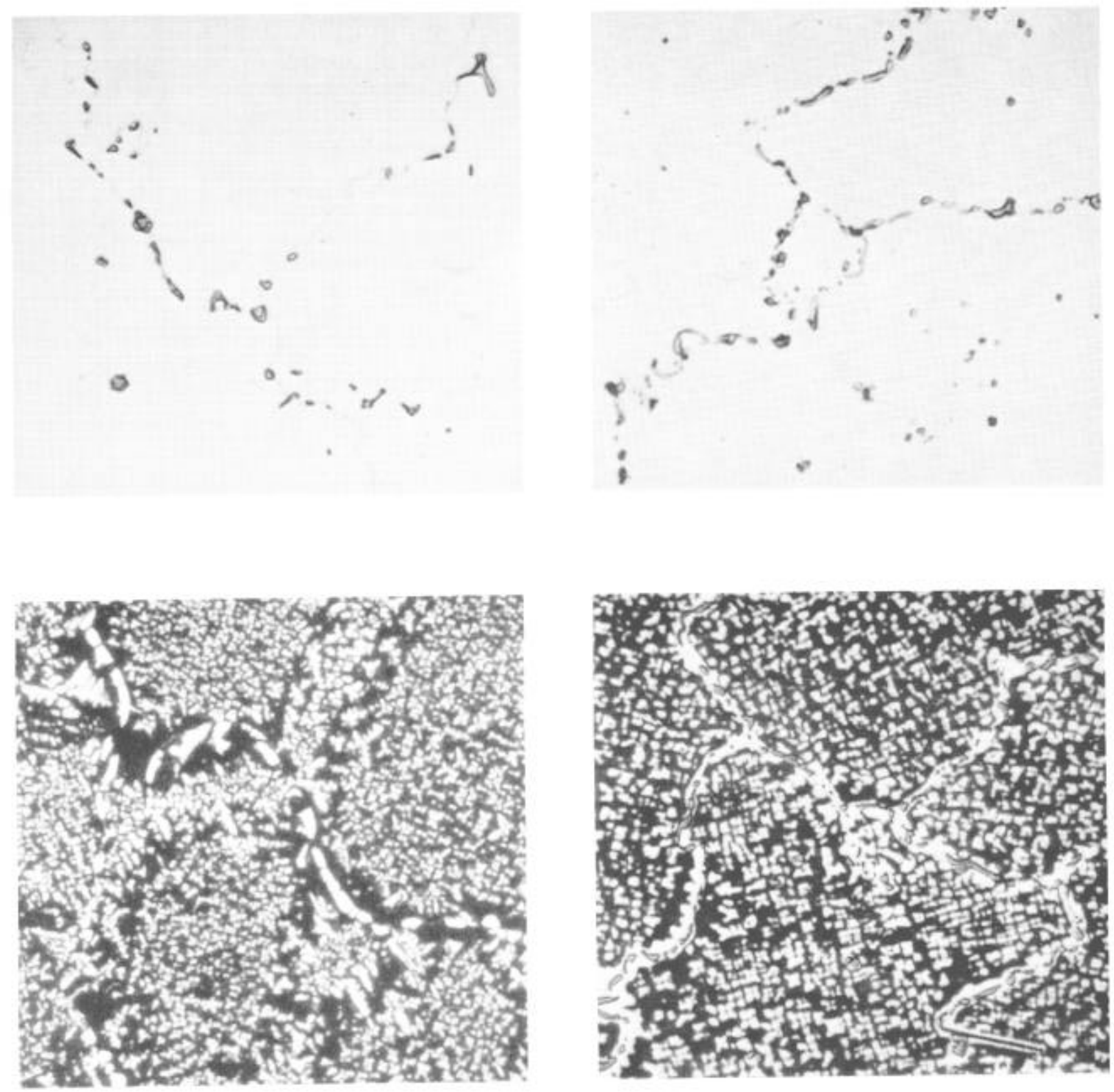

Figure 21. Microstructures of Rene' 77 (A) As Heat Treated and (B) After $1800^{\circ} \mathrm{F} / 500 \mathrm{Hr}$ Exposure Top - Etched in Murakami's. Bottom Etched in Phosphoric Acid. 1000X. 


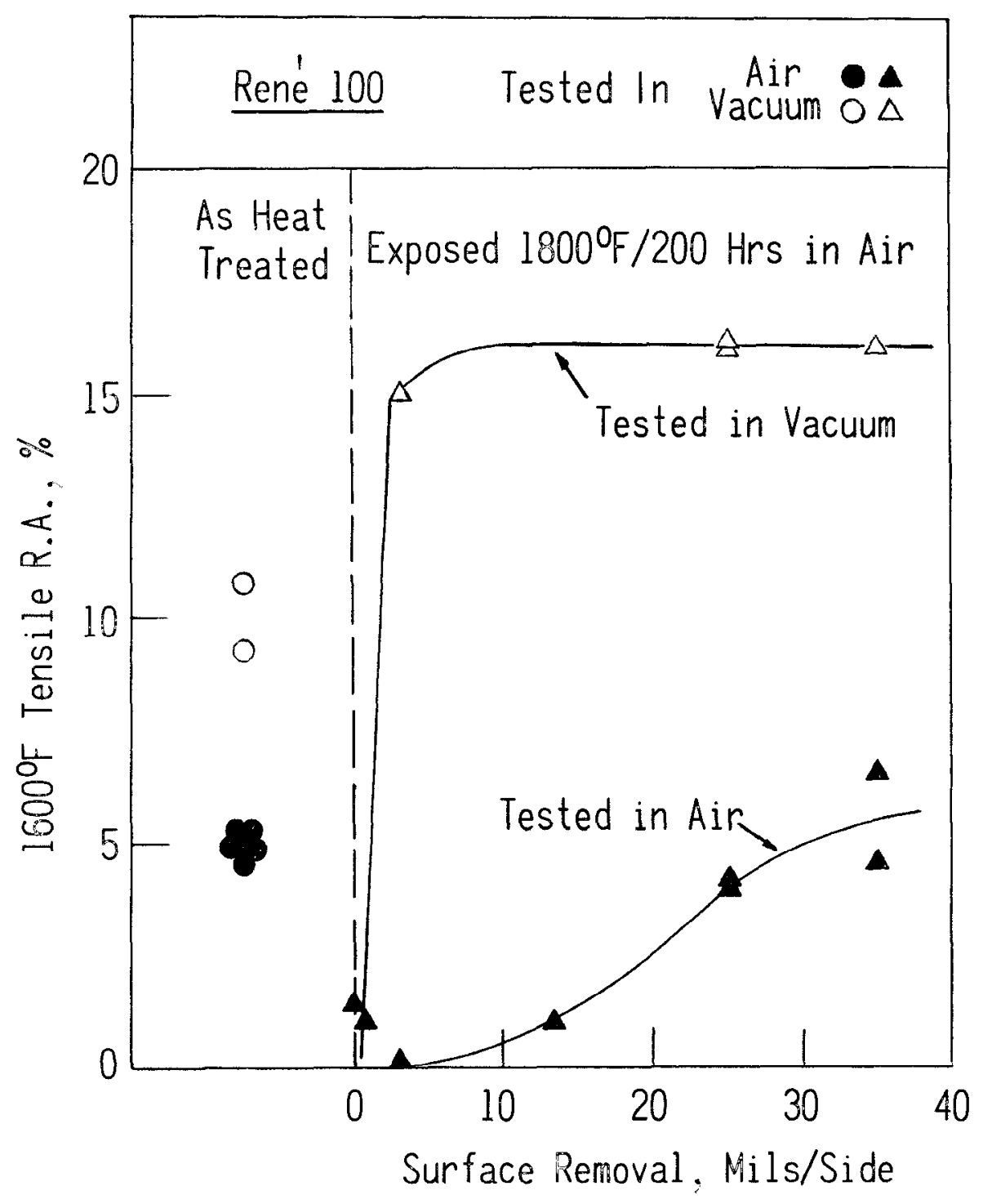

Figure 22. $1600^{\circ} \mathrm{F}$ Tensile Ductility of Rene' 100 in As Heat Treated Condition (Left) and after $1800^{\circ} \mathrm{F} / 200 \mathrm{Hr}$. Exposure in Air (Right). $\dot{\epsilon}=0.005 / \mathrm{Min}$. 
exposure at $1800 \mathrm{~F}$ for $200 \mathrm{hr}$, testing in air under a strain rate of $0.005 / \mathrm{min}$. resulted in virtually nil ductility in the as-exposed condition and barely 5\% R.A. after surface removal of $35 \mathrm{mils} / \mathrm{side}$. In comparison, a $3 \mathrm{mil} / \mathrm{side}$ removal, which eliminated the surface oxide only, was sufficient to raise the ductility to $15 \% \mathrm{R}$. A. when tested in vacuum. Note that the latter ductility was some $50 \%$ higher than that of the heat-treated condition tested in vacuum. This difference demonstrated again that the intrinsic ductility was enhanced, rather than impaired, by the high-temperature exposure. By the same token, the embrittlement observed upon testing in air must have arisen solely from static and/or dynamic interactions with the environment.

The microstructures of Rene' 100 before and after the exposure are shown in Fig. 23. The high concentrations of $\mathrm{Al}$ and $\mathrm{Ti}$ resulted in 64 volumc pcrcont of $\gamma^{\prime}$ (12) which was finely dispersed in the heattreated condition. This large amount of $\gamma^{\prime}$ probably accounted for the low ductility in air by providing a virtually continuous medium with which dynamic interactions could occur both intergranularly and intragranularly. Alternatively, Rene' 100 may represent a case in which the alloy was susceptible to surtace cracking and further, the $Y / \gamma$ interface itself was sensitive to air environment. In any event, the resulting propensity toward dynamic interactions provides a clue to the difficulty in eliminating the so-called ductility minimum in this alloy. The microstructural changes occasioned by the $1800^{\circ} \mathrm{F}$ exposure, $\mathrm{Fig}$. $23 \mathrm{~B}$, were characterized by intragranular $\gamma^{\prime}$ agglomeration and massive intergranular $\gamma^{\prime}$ network formation. As in the case of Rene' 80, these changes improved the intrinsic ductility on the one hand, while rendering the alloy vulnerable to air embrittlement on the other.

Results on Interaction Mechanism

Identification of Reacting Gas Species

In an attempt to identify whether oxygen or nitrogen caused contamination during air exposure, samples taken from the contaminated region of air-exposed Rene' 80 were repeatedly subject to gas analyses. These did not show any significant differences in gas contents from those of the heat-treated condition. Freshly-broken (intergranular) surfaces from air-exposed specimens were then examined in an Auger Electron Spectroscopic Analyzer to determine if the grain-boundary network was enriched in oxygen or nitrogen. This, too, failed to produce conclusive evidence. It appeared from these results that either of the interstilials had only small solubilities in the $\gamma^{\prime}$ phase.

The dynamic interactions presented a third approach in seeking a partial solution to the question, namely, by conducting the tensile test in nitrogen. Rene' 80 specimens vacuum exposed in the range of $1700^{\circ}$ to $1925^{\circ} \mathrm{F}$ to generate the $\gamma^{\prime}$ network were tested at $1600^{\circ} \mathrm{F}$ under a strain rate of $0.5 / \mathrm{min}$. which was known lo produce brittle failure in air. The testing procedure consisted of first evacuating the furnace chamber to 10-6 torr at room temperature, flashing with Union Carbide ultra-high-purity nitrogen ( $3 \mathrm{ppm}$ water vapor and $1 \mathrm{ppm} \mathrm{\textrm {O } _ { 2 }}$ ), reevacuating and heating the specimen to $1600^{\circ} \mathrm{F}$ in vacuum. Nitrogen was then readmitted to maintain a pressure of 1.5 psig. Five minutes were 


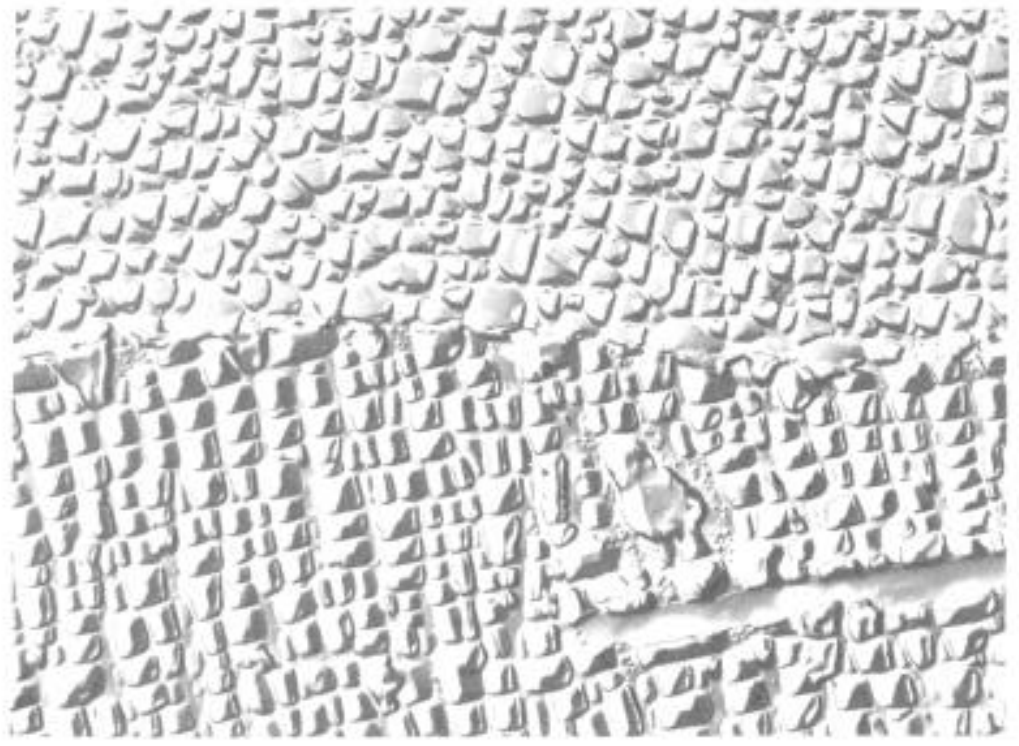

A.

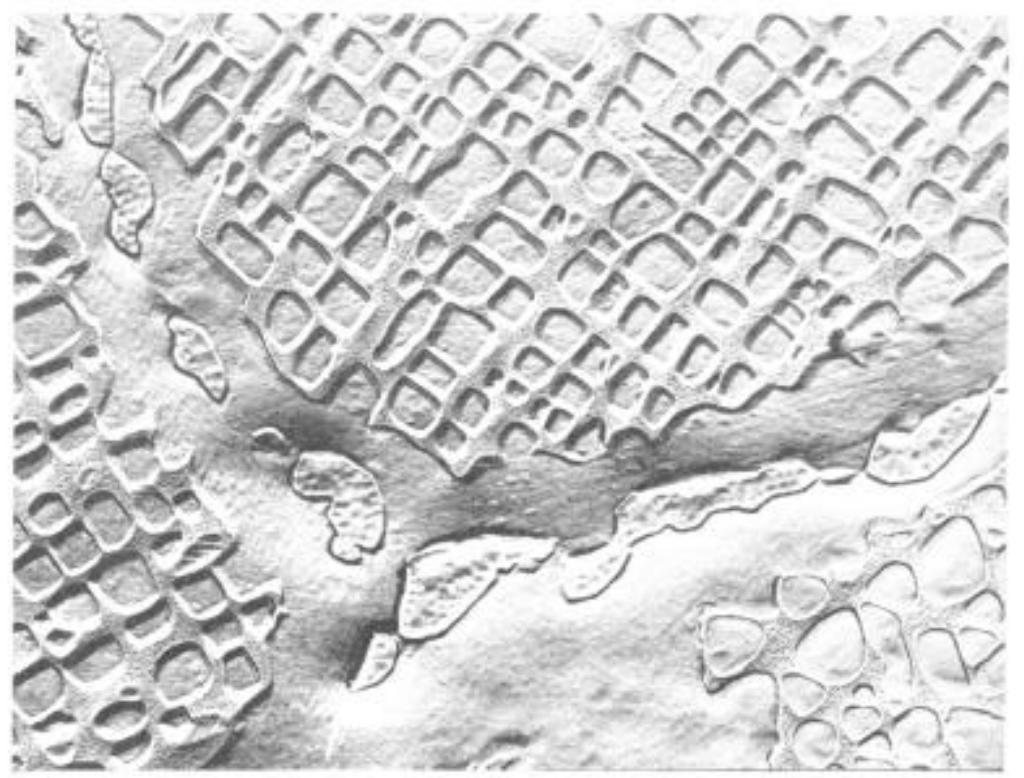

B.

Figure 23. Microstructures of Rene' 100 in (A) As Heat Treated and (B) after $1800^{\circ} \mathrm{F} / 200 \mathrm{Hx}$. Exposure. 5000X. 
allowed for temperature stabilization prior to loading. The test duration was of the order of $5 \mathrm{sec}$. The chamber was immediately evacuated after specimen failure to allow cooling in vacuum.

A total of three specimens were tested with the results given in Table 2. All three specimens exhibited as little ductility as if they had been tested in air. These results identified nitrogen as one of the offenders in causing dynamic interactions. The significance of this observation will be discussed later. Tensile tests in oxygen have not been performed to date. In view of the high reactivity of oxygen and until evidence to the contrary, it is assumed that both oxygen and nitrogen were participants to the interactions.

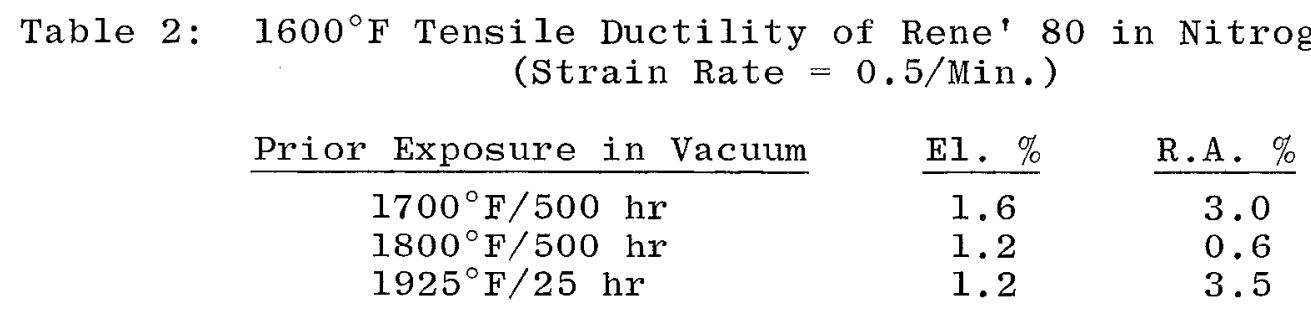

Ductility of $\mathrm{Ni} 3 \mathrm{Al}$

Since the $\gamma^{\prime}$ phase was believed to be the principal constituent which interacted with the air environment, tensile tests at $1600^{\circ} \mathrm{F}$ on as-cast monocrystalline and columnar-grained specimens of Ni3Al were conducted in both air and vacuum under strain rates of 0.005 to 1.0 per min. The results, given in Fig. 24, fell distinctly into two groups, separating the monocrystals, which averaged $37 \% \mathrm{R}$. A., from the columnargrained, which averaged 18\% R.A. Further, the ductility within each group was relatively independent of crystallographic orientation, testing atmosphere, or strain rate. The high ductility of the monocrystals contradicted directly the ductility minimum in the neighborhood of $1600^{\circ} \mathrm{F}$ reported for Ni3Al monocrystals by Copley, et a1(10) whose result is included in Figure 24. Reason for the discrepancy is not clear but could be related to the off-stoichiometry of Ni3Al and the prolonged high-temperature homogenization used in the investigation by Copley, et al. The insensitivity of $\mathrm{Ni}_{3} \mathrm{Al}$ to testing atmosphere and strain rate was also unexpected from the behavior of the superalloys studied in the present investigation. The lack of correlation, however, may be reconciled from two viewpoints. First, both the superalloys and the monocrystals indicated high intrinsic ductility of Ni3Al, which may favor internal crack initiation and propagation to failure, thus circumventing dynamic interactions in air. The lower ductility of columnar-grained $\mathrm{Ni} 3 \mathrm{Al}$ in either air or vacuum appeared to be primarily a consequence of intergranular failure (Fig. 25) either intrinsically or as a result of grain-boundary segregation of grown-in impurities. The second possibility related to the behavior of Ni3Al lies in the much more complex chemistry of the $\gamma^{\prime}$ phase in the superalloys. The grain-boundary $\gamma^{\prime}$ network in Rene' 80 , for instance, was found to contain small amounts of $\mathrm{Co}, \mathrm{Cr}$, Mo, and $\mathrm{W}$ in addition to $\mathrm{Al}, \mathrm{Ti}$, and $\mathrm{Ni}$. It may be that the sensitivity of $Y^{\prime}$ to oxygen and nitrogen, in terms of reactivity and embrittlement, was much aggravated by these alloying elements. 


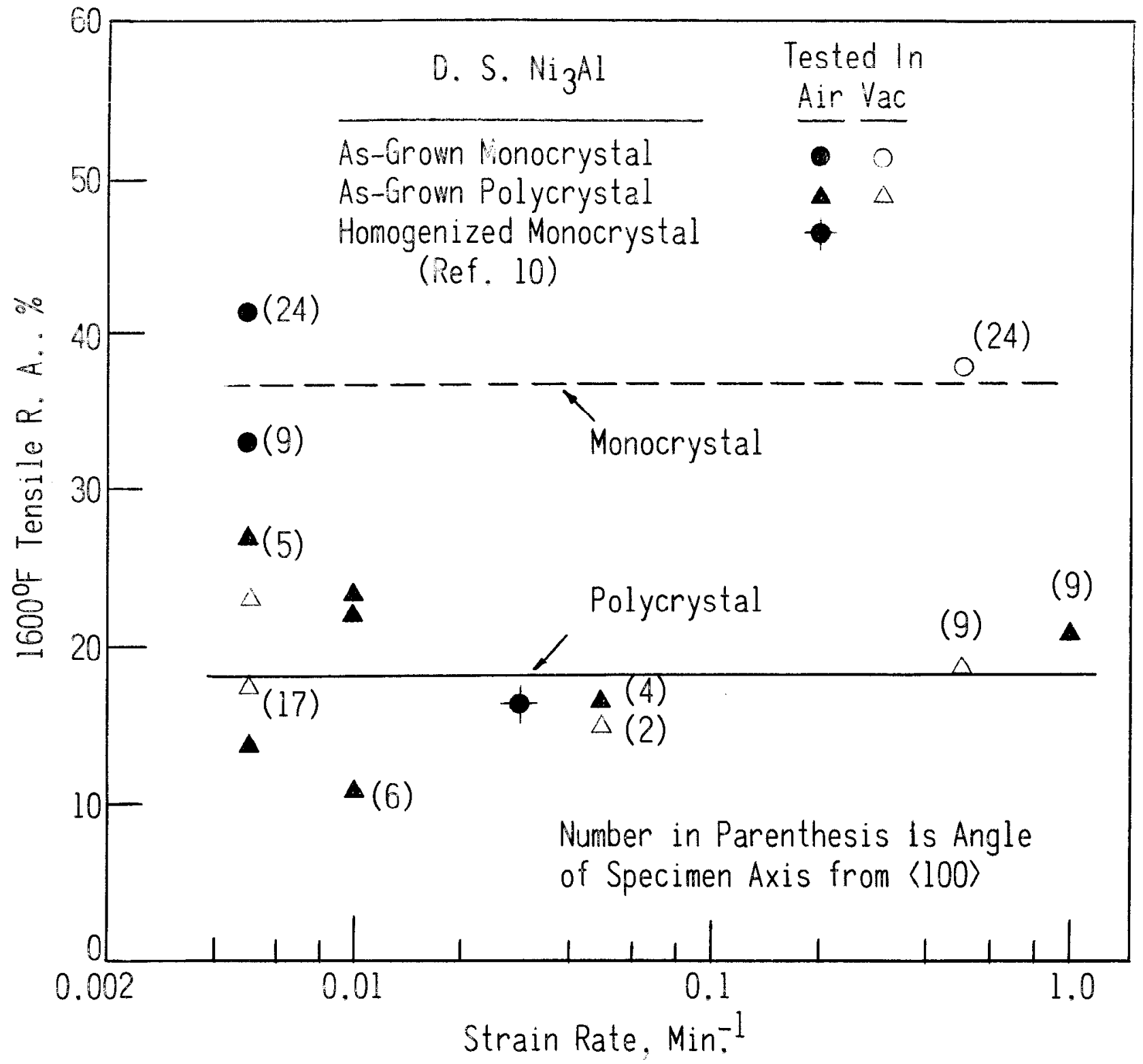

Figure 24. $1600^{\circ} \mathrm{F}$ 'Tensile Ductility of Directionally Solidified Ni $3^{\mathrm{Al}}$. 


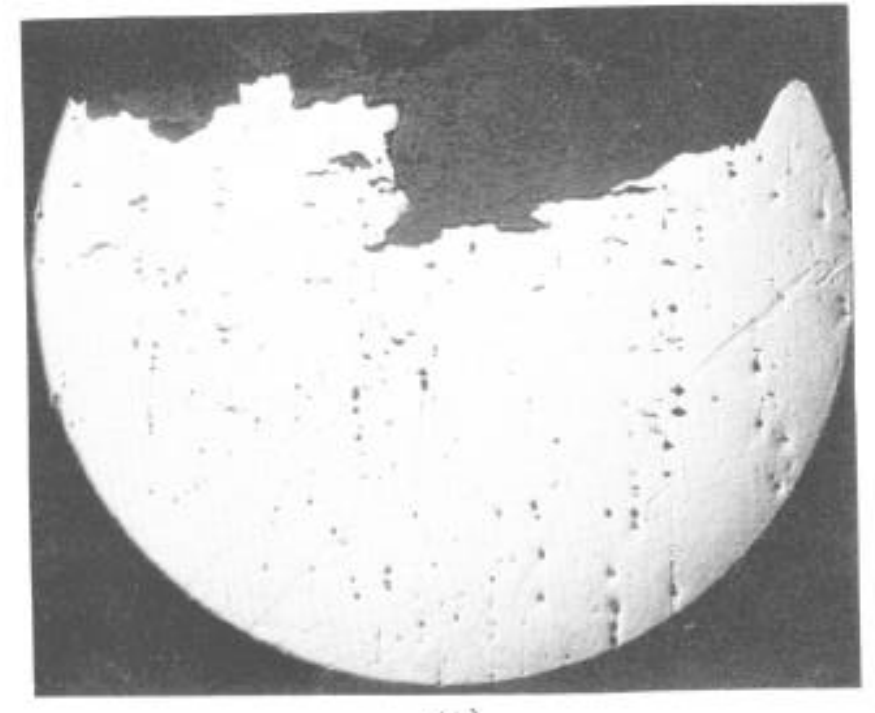

(A)

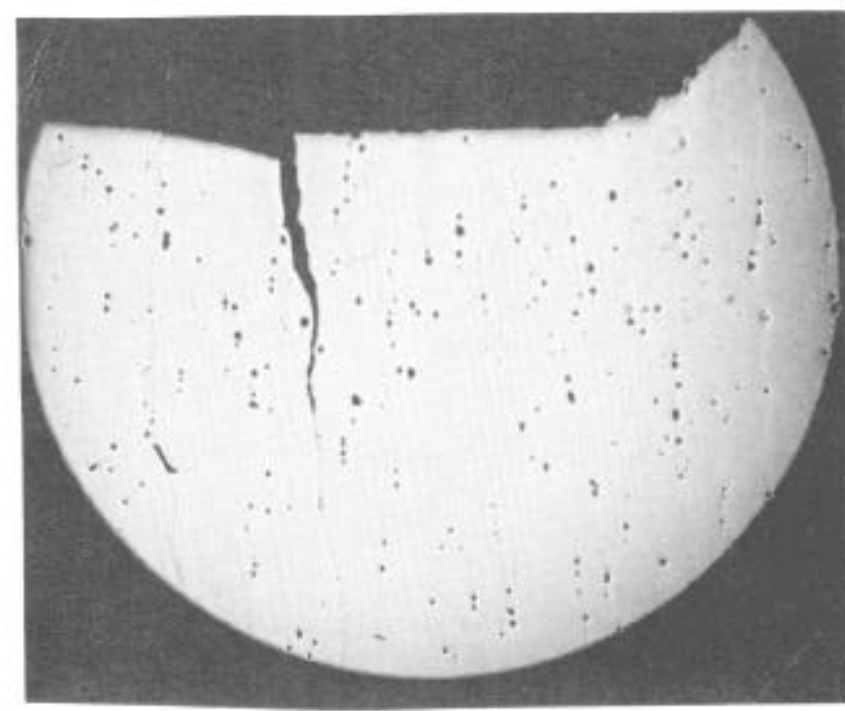

(B)

$\sum_{\tilde{\omega}}^{<}$

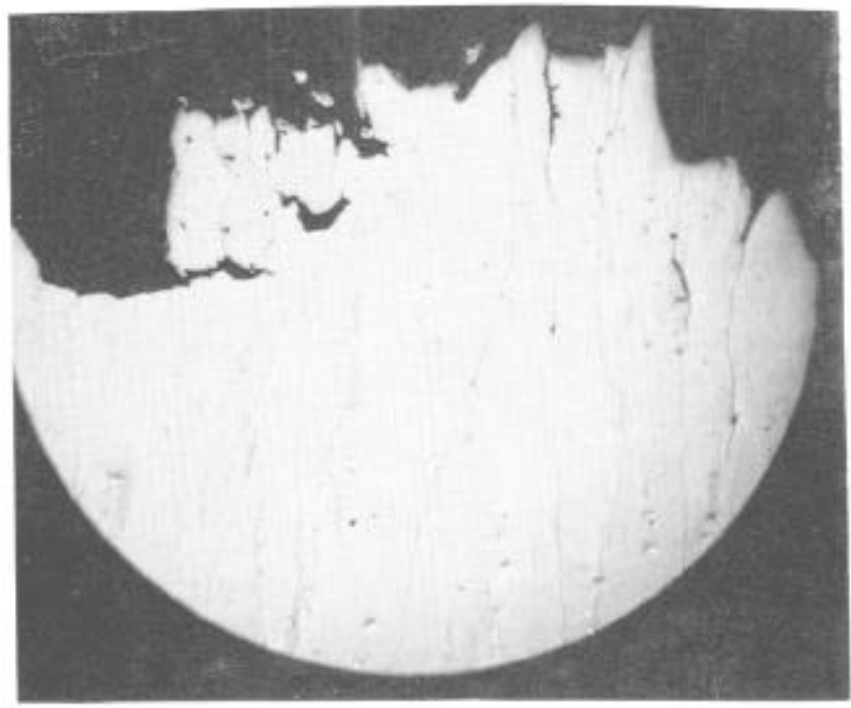

(C)

Figure 25. Tensile Fractures of $\mathrm{Ni}_{3} \mathrm{Al}$ at $1600^{\circ} \mathrm{F}$. 25X (A) Monocrystal 51\% R.A. (B) Polycrystả1. $17 \%$ R.A. (C) polycrystal. 11\% 
'The Rolle of $\mathrm{M}_{23} \mathrm{C}_{6}$

By virtue of the $\mathrm{MC}+\gamma \rightarrow \mathrm{M}_{23} \mathrm{C}_{6}+\gamma^{\prime}$ reaction, $\mathrm{M}_{23} \mathrm{C}_{6}$ co-existed with the $\gamma^{\prime}$ network in the grain boundaries. That neither phase adversely affected the intrinsic ductility of the superalloys was clearly witnessed by ductility retention when exposure and testing were carried out in vacuum. Whether the carbides participated in environmental interactions and thus tensile embrittlement, however, was not entirely clear. Preferential or accelerated oxidation of carbides was not observed in specimens exposed or tested in air. Severe embrittlement is empirically associated more often with a continuous phase, such as the $\gamma^{\prime}$ network, rather than discrete particles, such as the carbides. Since the $\gamma^{\prime}$ network and $\mathrm{M}_{23} \mathrm{C}_{6}$ could not be separated in the three superalloys studied, the role of $\mathrm{M}_{23} \mathrm{C}_{6}$ could not be separated in the three superalloys studied, the role of $\mathrm{M}_{23} \mathrm{C}_{6}$ was further explored by using Rene' $4 \mathrm{I}$, which could be aged to precipitate grain-boundary $\mathrm{M}_{23} \mathrm{C}_{6}$ without simultaneous formation of $\gamma^{\prime}$ network (1). Sheet tensile specimens with a gage section of 1.4 in. long, $0.25 \mathrm{in}$. wide, and $0.125 \mathrm{in}$. thick, were water quenched after solutioning at $2150^{\circ} \mathrm{F} / 1 / 2$ hour or $1950^{\circ} \mathrm{F} / 1$ hour. Some of these were subsequently aged at $1600^{\circ} \mathrm{F}$ for 24 or 64 hours to precipitate $\mathrm{M}_{23} \mathrm{C}_{6}$ carbides. Tensile tests were conducted at $1575^{\circ} \mathrm{F}$ under strain rate of $0.1 / \mathrm{min}$. in both air and vacuum with the results summarized in Table 3 . Regardless of the testing environment, the aged specimens containing grain-boundary $\mathrm{M}_{23} \mathrm{C}_{6}$ consistently displayed much higher ductility than the solutioned specimens. Microscopic examination indicated that failure was initiated by intergranular surface cracking. These results thus demonstrated the inertness of $\mathrm{M}_{23} \mathrm{C}_{6}$ in Rene' 41 and, indirectly, supported the contention that the $\mathrm{M}_{23} \mathrm{C}_{6}$ carbides did not play a significant role in the environmental interactions of the blade superalloys.

Table 3: Tensile Ductility of Rene' 41 at $1575^{\circ} \mathrm{F}$ (Strain Rate: $0.1 /$ Min.)

Heat Treatment

$\begin{array}{ll}\text { A. } & 2150^{\circ} \mathrm{F} / 30 \mathrm{Min} . \mathrm{W} . \mathrm{Q} . \\ \text { B. } & (\mathrm{A})+1600^{\circ} \mathrm{F} / 24 \mathrm{Hr} . \\ \text { C. } & 1950^{\circ} \mathrm{F} / 1 \mathrm{Hr} . \mathrm{W} . \mathrm{Q} . \\ \text { D. } & \text { (C) }+1600^{\circ} \mathrm{F} / 24 \mathrm{Hr} . \\ \text { E. } & \text { (C) }+1600^{\circ} \mathrm{F} / 64 \mathrm{Hr} .\end{array}$

\begin{tabular}{rr}
\multicolumn{2}{c}{ EI, \% } \\
\multicolumn{1}{c}{ Air } & \multicolumn{1}{c}{ Vac } \\
3.7 & 3.8 \\
18.2 & 16.2 \\
7.1 & 8.9 \\
6.0 & 7.7 \\
19.3 & 19.3 \\
27.7 & - \\
24.1 & -
\end{tabular}

\section{Discussion}

It is abundantly clear that tensile embrittlement of Rene' 80 is not intrinsic but environment-dependent. Specifically, the ductility loss is caused by intcractions of nitrogen and oxygen with the grainboundary $\gamma^{\prime}$ network which forms when the alloy is exposed within the stability range of $\mathrm{M}_{23} \mathrm{C}_{6}$. That the principal structural constituent vulnerable to the environmental interactions is the $\gamma^{\prime}$ network is concluded from the concerted evidence of: 
(1) immunity of the $Y$ phase in Rene' 80 monocrystals to embrittlement by air exposure,

(2) insensitivity of the as-heat-treated condition to testing in air in spite of predominantly intergranular mode of failure,

(3) intergranular fracture along the $y^{\prime} / \gamma^{\prime}$ interface after exposure,

(4) inertness of $\mathrm{M}_{23} \mathrm{C}_{6}$ carbides, and

(5) embrittlement of the exposed condition in nitrogen.

The last-named, in particular, is significant in favoring the $\gamma^{\prime}$, over the $\gamma$ phase as the reactant since nickel, at least at lowcr tempcraturcs, does not adsorb nitrogen(13). Tensile embrittlement of Rene' 41, which is attributed to oxygen adsorption on the $\gamma / \gamma$ interface, occurs in air but not in nitrogen( 3$)$. On the other hand, grain-boundary hardening of intermetallic compounds by both oxygen and nitrogen has been reported. (14)

In the present case, tensile embrittlement is shown to be induced by one or both of two modes: contamination by inward diffusion of the interstitials during air exposure and instantaneous reaction during testing in air. The activation energy of $67 \mathrm{kcal} / \mathrm{mole}$ associated with contamination is considerably higher than commonly found for interstitial diffusion, but is probably not unreasonable for such diffusion in an ordered lattice such as the $Y^{\prime}$ phase. In either mode of interactions, embrittlement of the host alloy reflects the embrittlement of the $\gamma^{\prime}$ grain-boundary network. Since gross or preferential oxidation is not involved, the most plausible mechanism of embrittlement appears to lie in reduction in surface energy and hence fracture strength of the $\gamma^{\prime}$ phase in qualitative accordance with the modified Griffith criterion:

$$
\sigma_{6}=\left(\mathrm{E} \gamma_{\mathrm{e}} / \mathrm{c}\right)^{1 / 2}
$$

where $\gamma e$ is the effective surface energy of the $\gamma^{\prime}$ phase; $c$, the crack length and $E$, the elastic modulus. The surface energy is reduced either by dissolution of the interstitials during air exposure or by their instantaneous adsorption upon testing in air. The solubility of the interstitials in the $\gamma^{\prime}$ phase appears small. That they can exercise a potent effect on ductility when in solution is consistent with the embrittlement effect caused by adsorption under conditions of dynamic interactions.

Once the grain-boundary $y^{\prime}$ network is formed, embrittlement can occur by dynamic interactions with or without prior contamination. On the other hand, dynamic interactions cannot occur unless the network is directly exposed to air as a consequence of surface cracking. This condition is always met in a previously-contaminated material when tested without surface removal. Propagation of the surface cracks, in turn, subjects the uncontaminated network to dynamic interactions, leading to low ductility as shown in Fig. 5. It is thus not surprising that even a $25-\mathrm{hr}$ air exposure at $1800^{\circ} \mathrm{F}$ is sufficient to embrittle a tensile specimen of 0.25 in. dia. although the contaminated zone $(0.008$ in./side) occupies only about $6 \%$ of the cross-sectional area. By the same token, high strain rates, which might otherwise be expected to minimize environmental interactions, are shown to have the opposite 
effect. The instantaneous nature of the dynamic interactions at first glance appears surprising, but is in accord with the expectations of the kinetic theory of gases. The number of gas molecules striking unit area in unit time is

$$
\mathrm{v}=P(2 \pi \mathrm{mKT})^{-1 / 2}
$$

where $\mathrm{P}$ is gas pressure; $\mathrm{m}$, weight of gas molecule; $\mathrm{K}$, Boltzmann's constant and $\mathrm{T}$, absolute temperature (15). At $1600^{\circ} \mathrm{F}$ and pressure of $1 \mathrm{~atm} ., \mathrm{v}$ is found to be approximately 1023 molecules per $\mathrm{cm}^{2}-\mathrm{sec}$. Since there are about $10^{15}$ atomic sites per $\mathrm{cm}^{2}$ of surface, the time required to saturate these sites is on the order of $10^{-8} \mathrm{sec}$. This time will probably bo longthoned by sticking factor and other considerations, but will remain far shorter than the test duration under the highest strain rate used.

By establishing the role of $\gamma^{\prime}$ network in Rene' 80 , the present work has also demonstrated susceptibility to tensile embrittlement in other blade alloys undergoing similar structural changes upon exposure. The results on Rene' 77 and Rene' 100 indicate that the propensity toward embrittlement varies with composition and, in addition to grain-boundary notwork, will gonerally increasc with the total volume fraction of the $y^{\prime}$ phase and the fineness of its dispersion. Since the network results from carbide reactions, it could be circumvented by removal of carbon from the alloys. This approach, however, tends to weaken the grain boundaries, leading to intrinsic brittleness. Unpublished work has shown, for example, that very low carbon Rene' 80 or Rene' 100 exhibits low tensile ductility at $1600^{\circ} \mathrm{F}$ even when tested in vacuum. Stabilization of the MC carbide by minor additions such as Hf may delay the carbide reactions and hence the onset of embrittlement. In comparison with compositional changes, controlled solidification offers a much more effective avenue in overcoming envixonmental interactions. Tensile embrittlement can be totally eliminated in monocrystals. In directionally-solidified polycrystals, embrittlement is significantly reduced in the longitudinal direction but is aggravated in the transverse direction.

Since environment-induced tensile embrittlement is a newlydiscovered phenomenon, its implications to turbine-blade applications have been and still are under critical scrutiny. The central questions are first, whether the embrittlement will indeed occur in turbine hardware and second, whether high-temperature exposure and environmental interactions affect other mechanical properties as drastically. Analysis of the information to date leads to several important observations. First, the potential of tensile embrittlement exists in all currently available turbine-blade alloys and these include U700/Rene' 77, IN-100/ Rene' 100, IN-713, B-1900, and Mar-M200, in addition to Rono' 80 . Second, the present findings indicate that tensile embrittlement is facilitated by the combined conditions of prior exposure, high strain rates, and rising stresses of such a magnitude as to cause plastic strains in excess of $0.2 \%$, at a region which is within the critical temperature range of 1550 to $1650^{\circ} \mathrm{F}$. It does not appear very likely that such a situation exists in the normal operation of turbine blades. Third, laboratory evaluation on Rene' 80 has not uncovered environmentinduced degradation in creep-rupture, high-cycle fatigue, and low-cycle fatigue properties. In addition, the impact resistance of Rene' 80 blades identical to those used in J79, TF39, and CF6 engines show 
neither unexpected nor unacceptable losses after engine or enginesimulated exposures. Fourth, complete sets of Rene' 80 blades have to date successfully accumulated 170,000 engine hours without material-related failure. Of even greater significance is the fact that failure attributable to tensile embrittlement has not been reported for turbine blades made of U700/Rene' 700, IN-100/Rene' 100, B-1900 or IN-713 after commercial and/or military services ranging up to millions of flight hours. Finally, the present investigation shows clearly that the intrinsic ductility of $\gamma^{\prime}$-strengthened superalloys is enhanced, rather than degraded, by high-temperature exposure.

Turbine blades made from such alloys will thus improve in ductility with service when protected from the hostile environment. This protection is provided by coatings which have already become an integral part of turbine blades in modern jet engines. In summary, these observations suggest that the prudent perspective toward tensile embrittlement should parallel that adopted for other well-known, surface-related phonomcna, namcly, salt stross corrosion in Ti-base alloys and oxidation/hot corrosion in $\mathrm{Ni}$ - or Co-base superalloys.

\section{Conclusions}

The loss of intermediate-temperature tensile ductility in Rene' 80 after high-temperature exposure is caused by interactions of nitrogen and probably also oxygen with the grain-boundary $\gamma^{\prime}$ network which forms as a result of the $M C+\gamma \rightarrow M_{23} C_{6}+\gamma^{\prime}$ reaction. Tensile embrittlement occurs in other $\mathrm{Ni}$-base turbine blade alloys which undergo similar structural changes upon exposure. The interactions can occur both statically by inward diffusion and dynamically by instantaneous adsorption of the interstitials when the $\gamma^{\prime}$ network is exposed to air via surface cracking. The resulting dissolution and/or adsorption of the interstitials is believed to lower the surface energy and fracture strength of the $Y^{\prime}$ phase, leading, in turn, to embrittlement of the host alloy through intergranular failure. In the absence of environmental interactions, the intrinsic ductility of Rene' 80, Rene' 77 and Rene' 100 is shown to be enhanced by formation of grain-boundary $\gamma^{\prime}$ network and $\mathrm{M}_{23} \mathrm{C}_{6}$ and agglomeration of the intragranular $\gamma^{\prime}$ dispersion. Tensile embrittlement is thus shown to be preventable by coatings, especially when the latter are sufficiently thick and ductile to sustain and confine surface cracking under high strain rates.

\section{Acknowledgements}

This paper is dedicated to the late Louis V. Owen who assisted throughout the entire investigation with outstanding devotion to experimental details and accuracy. 


\section{$\underline{\text { References }}$}

1. H。E. Collins, ASM Trans. Qtx., 62 (1), 1969. p. 82 .

2. I. Kramer and L. J. Demer, Effects of Environment on Mechanical Properties of Metals, Progress in Materials Science, vol. 9 (3), 1961.

3. M. Prager, Ph. D. Dissertation, Univ. of Calif., Los Angeles. 1969.

4. P. J. Duquette and M. Gel1, Met. Trans., 2 (5), May 1971. p.1325.

5. F. E. Organ and M. Gell, Met. Trans., 2 (4), April 1971. p.943.

6. J. K. Tien and R. P. Gamble, Met. Trans., 2 (7), July 1971. p.1933.

7. L. Coffin, "The Effect of Vacuum on High-Temperature, Low-Cycle Fatigue Behavior of Structural Materials", to be published in Proceedings of International Conference on Corrosion and Fatigue held in June 1971 .

8. E. W. Ross, Metal Progress, March 1971. p.93.

9. P. H. Thornton, R. G. Davies and T. L. Jonsten, Met. Trans. 1 (1), Jan. 1970. p.207.

10. S. M. Copley and B. H. Kear, Trans. AIME, 239, July 1967. p.977.

11. E. H. Van Der Molen, J. M. Oblak and O. H. Kriege, Met。 Trans. 2 (6), June 1971. p.1627.

12. P. Aldred, Private communications, General Electric Co.

13. L. H. Germer and A. V. MacRae, J. Phys. Chem., 36 (3), Mar. 1962. p. 1555 .

14. J.H. Westbrook and D. L. Wood, J. Inst. Metals, 9l, 1962. p.174.

15. S. Glasstone, K. J. Laider and H. Eyring, The Theory of Rate Processes, McGraw-Hill Book Co., Inc., New York, 1941. 